Copyright by

Erin Marie Keys

2014 
The Thesis committee for Erin Marie Keys

certifies that this is the approved version of the following thesis:

\title{
Variable Speed Drives for Power Factor Correction in the Water Sector
}

\author{
APPROVED BY \\ SUPERVISING COMMITTEE:
}

Michael E. Webber, Supervisor

Ross Baldick, Co-Supervisor 


\title{
Variable Speed Drives for Power Factor Correction in the Water Sector
}

\author{
by \\ Erin Marie Keys, B.S.E.
}

\author{
THESIS \\ Presented to the Faculty of the Graduate School of \\ The University of Texas at Austin \\ in Partial Fulfillment \\ of the Requirements \\ for the Degree of
}

\section{MASTER OF SCIENCE IN ENGINEERING}

The University of Texas at Austin

August 2014 
Dedicated to Dr. Webber, who recruited me back to UT to pursue my MS degree. The respect I have for Dr. Webber - as an educator, a motivator, a communicator, and a human being - is immeasurable. My acceptance into the National Science Foundation Integrated Graduate Education Research and Traineeship (IGERT), as well as the Webber Energy Group (WEG), was a gift. I have cultivated lifelong friendships in WEG and IGERT, and am humbled to count myself among these groups' members. Also dedicated to my colleagues at General Electric who helped convert me from a by-the-book engineer to a big-picture strategist. In particular, I would like to thank Mike Volpe for introducing me to power economics, and Nick Miller for coaching me on the subject's finer technical details. Because of these two individuals, I was motivated to seek higher education to divert my career from one focused on power generation to one focused on energy management and smart grid. Finally, dedicated to my mom and dad; I more fully comprehend the magnitude of their support everyday. 


\section{Acknowledgments}

The author would like to thank IGERT and the Texas State Energy Conservation Office (SECO) for their sponsorship of this project. She would also like to thank experts at Austin Water Utility (David Greene, Joe Smith, Tony Rizk, Matt Scharf and Harry Williams) for their provision of data, guidance, and introduction to Specific Energy (Perry Steger and David Pierce), a start-up based in Austin, Texas whose empirical findings were integral to the calibration of the dynamic model. The author would also to thank experts at Austin Energy (Luis Cabeza, Clayton Stice and Linda Rickard), the University of Texas Center for Electromechanics (Fabian Uriarte), Pecan Street (Scott Hinson) and General Electric (John McDonald) for their intellectual contributions. Further, she would like to thank her advisors (Ross Baldick and Michael Webber) for their support, both academically and professionally. Finally, the author would like to acknowledge the intellectual contributions of her colleagues in the Webber Energy Group (WEG) and IGERT. 


\title{
Variable Speed Drives for Power Factor Correction in the Water Sector
}

\author{
Erin Marie Keys, M.S.E. \\ The University of Texas at Austin, 2014 \\ Supervisors: Michael E. Webber \\ Ross Baldick
}

While solar photovoltaic (PV) panels can offset fuel, emissions, and water use at the power plant, high levels of installed rooftop PV capacity can have negative impacts on the stability and efficiency of the local grid because of power factor (PF) degradation. Specifically, electric utilities have noted voltage fluctuations from solar PV that occur more dynamically than legacy, electromechanical voltage regulation solutions like capacitor banks are designed to correct. At the same time, distributed power electronics devices like inverters can provide the type of dynamic voltage support that utilities seek to maintain reliability while juggling load growth and a greening grid. Using data from Pecan Street Inc. Smart Grid Demonstration Project in Austin, Texas and Austin Water Utility (AWU), this research examines the potential for a three-phase, four quadrant variable speed drive (VSD) in the water sector to provide PF correction to a load pocket of 63 homes experiencing varying levels of PV penetration. In the analysis, the VSD is not reserved for voltage support; instead it is predominantly used to drive a 30 kilowatt $(\mathrm{kW})$ centrifugal sewage pump. The simulation determines the degree to which the VSD can restore PF to a threshold of 0.95 , slightly below the targeted value for Austin's electric utility. Further, the economic viability of using the VSD as a grid device is explored by comparing the 
per unit cost of the PF correction it provides to a current utility solution for dynamic volage regulation. 


\section{Table of Contents}

Acknowledgments $\quad$ V

Abstract $\quad$ vi

List of Tables $\quad$ x

List of Figures $\quad$ xi

Chapter 1. Introduction \& Motivation 1

Chapter 2. Background 4

2.1 AC Power . . . . . . . . . . . . . . . . . . . . . 5

2.2 Distribution vs. Transmission . . . . . . . . . . . . . . . 7

2.3 Traditional Voltage Regulation . . . . . . . . . . . . . . . . . 8

2.4 Voltage Regulation With Distributed Energy Resources . . . . . . . . 10

2.5 Variable Speed Drives . . . . . . . . . . . . . . . . . . . . . . 12

2.6 Pump Theory . . . . . . . . . . . . . . . . . . . 14

Chapter 3. Computational Approach \& Analysis 18

3.1 Data Utilized . . . . . . . . . . . . . . . . . . . . . . . . . . 18

3.2 Structure \& Programs Employed . . . . . . . . . . . . . . . . . . 21

3.3 Data Cleanup . . . . . . . . . . . . . . . . . . . . 21

3.4 Load Pocket Characterization . . . . . . . . . . . . . . . 23

3.5 Data Digitization and Dynamic Model Creation . . . . . . . . . . . . 24

3.6 Introduction of Electrical Efficiency . . . . . . . . . . . . . . . . . . 29

3.7 Dynamic Model Calibration . . . . . . . . . . . . . . . . . . 31

3.8 Reactive Power Compensation From the VSD . . . . . . . . . . . . . 32

3.9 Energy and Demand Savings From Using a VSD . . . . . . . . . . . . 34

3.10 Utility Payment . . . . . . . . . . . . . . . . . . . . . 36

Chapter 4. Results 38

4.1 Pump Operation With a VSD . . . . . . . . . . . . . . 38

$4.2 \mathrm{PF}$ Improvement . . . . . . . . . . . . . . . . . . . . . . . . . . . . . . . . . . . 40

4.3 Economic Viability of the Proposed Solution . . . . . . . . . . . . . . 44 
Chapter 5. Conclusion

Bibliography 


\section{List of Tables}

3.1 Integral to the research are datasets from AWU and Pecan Street . . 20

3.2 VSD efficiency degradation under partial loading according to EERE [1]. 30

3.3 Rattan Creek's monthly electricity bill is comprised of $E, F, D, D Y, R$ and $C$ charges that differ by demand class and season [2] . . . . 35

4.1 PF correction is highest (on a percentage basis) for hours during which $\mathrm{PV}$ generation is also highest. . . . . . . . . . . . . 


\section{List of Figures}

2.1 The components of $\mathrm{AC}$ power can be represented using the Power Triangle. . . . . . . . . . . . . . . . . .

2.2 Per unit costs of various voltage regulation devices utilized by electric utilities according to Oak Ridge National Lab [3]. . . . . . . . . . . .

2.3 Reduction of friction head competes with a lower pump efficiency for system curves dominated by static head. . . . . . . . . . . . . .

3.1 $\mathrm{PF}$ is measured at the lateral service entrance assuming that the VSD and load pocket coincide at this location. . . . . . . . . . . . 19

3.2 Recreation of diurnal curve using piecewise linear interpolation . . . . 26

3.3 Sewage pumps operate in conjunction with a wet well. . . . . . . . . 27

3.4 Digital recreation of system and efficiency curves using polyfit yields $R^{2}$ values of 0.99 and 0.97 , respectively. . . . . . . . . . . . . . . . . 29

3.5 The pump system includes mechanical and electrical components. . . 30

4.1 The headroom available in a sewage pump can be used to provide PF correction to a community with high PV DG penetration. . . . . . . . 39

4.2 The wet well fills and empties as a function of net flowrate. . . . . . . 40

4.3 As PV penetration increases, PF degrades more substantially (from 0.87), especially during the hours of peak PV generation. . . . . . . .

4.4 PF correction from the VSD is least effective during the summer when load and thus reactive power demand are highest (for a given PF). . .

4.5 PF correction from the VSD is competitive with exiting utility solutions at a 3.5 customer payback. . . . . . . . . . . . . . . . 


\section{Chapter 1}

\section{Introduction \& Motivation}

Since 2006, the rate of residential solar photovoltaic (PV) installations has steadily increased as a result of declining panel costs and sustained incentive programs [4]. In 2006, a PV installation occurred every 80 minutes; by 2016, it is projected that a PV installation will happen every 83 seconds [4]. The Pecan Street Smart Grid Demonstration (Pecan Street), which includes a community in Austin, Texas with approximately 180 rooftop PV installations out of 735 homes, represents a high level of PV penetration that could become more commonplace if current installation trends continue [5]. Studies conducted with Pecan Street data have the potential to illuminate what grid operators can expect as more PV installations come online.

While the renewable generation can offset fuel, emissions and water use at the power plant, large concentrations of PV DG can have negative impacts on the stability of the local grid [6]. Specifically, environmental conditions like cloud cover lead to intermittent PV power production and voltage fluctuations that occur more dynamically than legacy, electromechanical voltage correction solutions such as capacitor banks are designed to handle [6]. Consequently, these assets are being operated more frequently than intended, causing additional maintenance or early replacement [6].

Utilities are searching for ways to mitigate these voltage fluctuations, especially since the entities are obligated to maintain voltage within a certain range as prescribed by the American National Standards Institute (ANSI) [7]. If not addressed, voltage 
swings can contribute to interruptions in electric service like the 2003 blackout in the northeastern US and Canada [3]. Increasing electricity demand exacerbates these grid reliability issues, making additional sources of local, dynamic voltage support critically needed as power consumption rises in some areas of the grid [8].

Power electronics devices are well suited to address dynamic voltage fluctuations [9]. In fact, the newly amended version of the industry standard IEEE 1547 will allow distributed energy resources (DER) such as "smart" inverters to regulate voltage. Under the current version of the standard, PV DG can degrade power quality due to a restriction on the inverter's operation [10]. Four quadrant (i.e. "active front end" or AFE) variable speed drives (VSDs), which improve consumption power quality and can reduce energy consumption of motor-drive loads, could regulate voltage under the amended version of IEEE 1547, as well. VSDs are gaining popularity, but their penetration among motor drives in the US remains below $10 \%$ as of 2002 , the vintage of the latest study quoting such a statistic [11]. AFE VSDs are even less common, though some industrial facilities are adopting the more advanced technology for the two aforementioned reasons, as well as to reduce extraneous thermal losses caused by the transport of additional reactive current according to Ohm's Law $\left(P=I^{2} R\right)[3]$.

As a geographically distributed and centrifugal motor load, sewage pumping could be an appropriate application of VSD technology to achieve energy savings and improve distribution grid power quality (e.g. power factor, or PF). In particular, sewage pumps are located throughout a city and likely coincident with stressed portions of the distribution grid. Further, with $12.6 \%$ of US annual energy use attributable to water related processes, energy efficiency in the water sector represents an opportunity to decrease national energy consumption [12]. 
Combining grid demand and PV generation data from Pecan Street in Austin, Texas with operating parameters for a 30 kilowatt $(\mathrm{kW})$ sewage pump provided by Austin's municipal water utility (AWU), this research examines the PF correction potential of a three-phase, AFE VSD applied to the pump. When the VSD is not supplying power to the pump, it provides PF correction to a load pocket of 63 homes with varying levels of PV penetration. Demand response of power for the sewage pump in favor of PF correction is not considered. The simulation conducted on the VSD determines the degree to which the device can restore PF to a relaxed Austin Energy threshold of 0.95. A per unit cost of the VSD-supplied PF correction is also explored by using a STATCOM, a historical utility option for dynamic voltage regulation, as the benchmark for a viable solution.

The proposed PF correction solution lives at the intersection of an energy efficiency opportunity, water management strategy, and grid reliability challenge. Therefore, each of the following chapters of the manuscript not only discusses these themes individually, but also their novel overlap which represents the gap filled by this research. The second chapter provides background on the power grid, including the role of voltage regulation. Further, relevant details on VSD technology and pump theory are presented. The third chapter details the analytical approach - including dataset cleanup, code construction, and equation selection - to determining the PF correction potential of the VSD, as well as the per unit cost of the grid support it provides. The fourth and final chapters include results and conclusions, respectively. 


\section{Chapter 2}

\section{Background}

Since the 19th century "War of the Currents" in which Nikola Tesla and Thomas Edison endorsed competing views on how to move electricity most efficiently from supply to load, the predominant platform of electricity transmission throughout the world has been alternating current (AC) [13]. The concluding factor of this debate was the fact that high-voltage electricity transmission leads to less power losses, and $\mathrm{AC}$ voltage magnitude can be more easily elevated to high voltage and lowered again than can direct current (DC) voltage magnitude [13]. Ironically, the "War of the Currents" is not yet over due to the growing utilization of DG in the form of solar PV panels and batteries, both technologies that produce DC power [13]. For now, though, AC power is the standard means of transmitting electricity, and thus these DC power sources must connect to the grid with inverters [13].

Voltage regulation remains a crucial parameter in maintaining efficient and reliable power delivery. Optimizing voltage magnitudes not only reduces transmission losses, but also prevents voltage collapse (e.g. blackouts) and damage to load-side power equipment [14]. As a result, ANSI requires that electric service be delivered within $\mathrm{a}+/-5 \%$ band of the specified operating level [7]. Some utilities have aimed for higher efficiency goals by implementing Conservation Voltage Reduction (CVR) programs in which voltage magnitudes are constrained to even tighter limits than ANSI standards $[7,15]$. It is these utilities like San Diego Gas and Electric (SDGE) that can face the most difficulty maintaining voltage at preferred levels when external 
factors like PV DG cause voltage fluctuations beyond the scope of typical voltage regulation solutions [7].

\subsection{AC Power}

AC power is comprised of two sinusoidal waves: current and voltage [8]. These waves pulsate, though not necessarily in phase (e.g. simultaneously peaking), at the frequency of the power grid, which is 60 cycles per second $(\mathrm{Hz})$ in the United States (US) [16]. The product of the "root mean square" (RMS) values of current and voltage determines apparent power $(S)$, which is measured in Volt-Amperes (VA) [8]. RMS values relate to peak values according to $V_{r m s}=V_{m} / \sqrt{2}$, where $V_{m}$ is the peak amplitude of a sinusoidally varying quantity [17]. Two types of power comprise $S[8]$ :

1. Active power $(P)$, measured in Watts $(\mathrm{W})$.

2. Reactive power $(Q)$, measured in Volt Amperes Reactive (VAR).

The relationship between these components of power is defined by the Power Triangle, where $P$ is the horizontal axis, $Q$ is the vertical axis, and $S$ is the hypotenuse [18]. Figure 2.1 illustrates this breakdown of AC power, whose mathematical relationship is defined by Equation 2.1, or the Pythagorean Theorem [18].

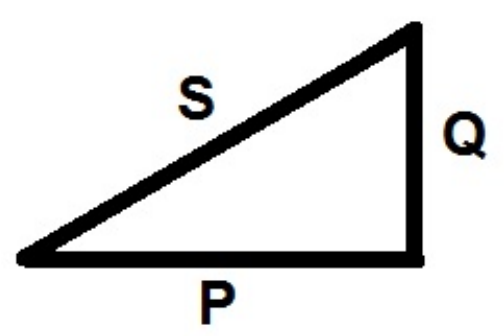

Figure 2.1: The components of $\mathrm{AC}$ power can be represented using the Power Triangle. 


$$
S^{2}=P^{2}+Q^{2}
$$

$P$ is the average power delivered and accomplishes useful work [14]. In this case, the peaks of the contributing current and voltage waveforms occur simultaneously and the power is purely resistive [19]. On the other hand, $Q$ represents the magnitude of a flow that has zero average value and is the result of energy storage [20]. This type of power is purely reactive and comprised of current and voltage waveforms whose peaks occur $90^{\circ}$ apart [19]. This "phase shift" $(\varphi)$ between current and voltage waveforms is quantified by power factor $(\mathrm{PF})$, which is also the ratio of $P$ to $S[21]$. When $\mathrm{PF}$ is less than unity, a portion of the power delivered is reactive. Equations 2.2 and 2.3 define these different representations of PF [21].

$$
\begin{aligned}
P F & =\frac{P}{S} \\
& =\cos (\varphi)
\end{aligned}
$$

PF can be leading or lagging [3]. In other words, the current waveform can reverse directions before or after the voltage waveform. A leading PF indicates the prevalence of capacitance over inductance and can lead to a voltage drop; whereas, a lagging PF indicates the prevalence of inductance over capacitance and can lead to a voltage boost [3]. Although PF and voltage magnitude are closely linked, they are difficult to mutually optimize [8].

Utilities must comply with PF requirements of the Independent System Operator (ISO) or Regional Transmission Operator (RTO) under which they operate [22]. These operators coordinate the flow of power from generators to loads and have a keen interest in maintaining $\mathrm{PF}$ within a certain range since the parameter impacts 
electricity transport as well as the extent of line congestion. For example, the Electric Reliability Council of Texas (ERCOT) recommends that Austin Energy (AE) maintain a lagging $\mathrm{PF}$ of 0.97 at the distribution substation [22]. If $\mathrm{AE}$ is unable to comply with this provision then ERCOT has the authority to levy fines on the utility [22].

\subsection{Distribution vs. Transmission}

The bulk AC power system includes three phase lines and single phase lines [23]. Three phase lines carry waves of $\mathrm{AC}$ power whose cycles are $120^{\circ}$ out of phase; whereas, single phase lines carry only one wave of AC power [16]. Transmission networks, which operate at high voltages and deliver electricity from generators to load centers, utilize three phase lines [23]. Distribution networks, which operate at lower relative voltages and deliver electricity to consumers within load centers, utilize three phase and single phase lines [23]. In particular, three phase lines called feeders emanate from the distribution substation [23]. From there, single phase lines called laterals deliver power to residential loads [23].

The distribution substation utilizes transformers to convert voltage magnitudes to those required for transmission or distribution; in this way, the substation acts as the gateway between the two networks [23]. Transformers operate on the basis of electromagnetic induction and include two sets (primary and secondary) of windings, or coils of typically copper wire, through which current flows [23]. Current enters through the primary side and exits through the secondary side [23]. A step-down transformer steps down voltage and steps up current; whereas, a step-up transformer steps up voltage and steps down current.

Distribution lines also inhibit smaller ratios of reactance $(X)$ to resistance 
$(R)$ than do transmission lines [24]. Reactance and resistance are both electrical properties quantifying degrees of opposition to particular phenomena: a change in current due to inductance in the case of reactance, and the passage of current through a conductor in the case of resistance [19]. Together, reactance and resistance comprise impedance [19]. As a result of this smaller $\mathrm{X} / \mathrm{R}$ ratio, the voltage magnitude on distribution lines is more sensitive to external factors and can consequently be a finicky parameter to regulate [24].

\subsection{Traditional Voltage Regulation}

Voltage regulation is one of various types of ancillary services [14]. Ancillary services exist to support the basic operation of the power grid and are necessary to ensure that electricity supply instantaneously meets electricity demand at every moment of service [14]. Whereas other types of ancillary services are compensated based on market-based design, reactive power provision is typically governed by administrative procedure and compensated in the form of an annual, socialized capacity payment or a monthly revenue requirement depending on the type (utility or nonutility) of generator [14]. In the US, compensation only occurs at the transmission level. Suppliers of reactive power at the distribution level are either owned by the utility or go unpaid for providing the service [3].

Utilities use an array of solutions to regulate voltage. Though not the focus of this research, transmission level voltage regulation is important to consider to gain context for the entire utility strategy for maintaining grid reliability. Synchronous condensers, which are generators outfitted with a clutch that allows disconnection from the prime mover, can supply or absorb reactive power [3]. Further, generators providing active power can simultaneously supply reactive power, but only as much 
as their $D$ curves will allow [3]. A $D$ curve defines the thermal limits of a generator's components (armature, field, and core) such that overheating is avoided [3].

Both of these generator-based solutions are dynamic in nature. Other transmissionlevel, dynamic solutions include a family of devices classified as Flexible AC Transmission Systems (FACTS) [3]. These devices, including the Dynamic VAR system (D-VAR), Static Compensator (STATCOM), and Static VAR Compensator (SVC), provide rapid voltage regulation exactly when and at what magnitude utilities require it [3].

Historically, voltage regulation at the distribution level has been dominated by static solutions. These solutions provide incremental correction rather than dynamic, tailored support [3]. A common example of this type of solution is a shunt capacitor, or "capacitor bank." Capacitor banks are considered the most economical, standalone voltage correction solution and can be purchased over a wide range of sizes depending on the amount of reactive power needed [3]. These devices are typically activated based on the time of day or environmental conditions like temperature [25]. Although automated switching is increasingly being applied to capacitor banks, these solutions are still limited by their inherently static nature [26]. As an additional downside, the effectiveness of these solutions depends on line voltage [9]. Thus, they are least useful when needed most [3]. Load tap changers, which exist inside distribution transformers and adjust voltage on the primary or secondary side by changing the number of windings employed, exhibit similar drawbacks [14].

Although dynamic devices are better equipped to handle the voltage fluctuations caused by PV DG, they are nearly nonexistent on the distribution network outside of PV DG inverters themselves. Only since 2010 have utilities started to install the equivalent of FACTS devices (e.g. standalone power electronics based 
solutions) on distribution lines [27].

\subsection{Voltage Regulation With Distributed Energy Resources}

Standalone power electronics based solutions are not the only option for dynamic, distribution-level voltage correction. Distributed energy resources (DER) have comparable capability but are unable to participate in voltage regulation, despite the benefit of supplying reactive power locally to limit line losses [9]. In particular, IEEE 1547 has historically prohibited DER with electric power systems from 1) operating at non-unity PFs and 2) remaining interconnected to the grid during a frequency event (i.e. when frequency dips below or rises above the typical 60 cycles per second) [28]. As a result, PV DG inverters, although they are inherently capable of supplying reactive power, are currently producing only active power.

Projected to begin in late 2014, an amended version of IEEE 1547 will allow PV DG installations to adjust their PFs [28]. Utility-scale PV installations in the US already incorporate this capability, as do PV DG installations in Germany [29]. It is unclear how effective the amendment will be at eliminating the roadblocks associated with distribution level voltage regulation in the presence of high PV penetration and increased load growth. As electricity demand on a line increases, reactive power absorption also increases, which exacerbates instances of voltage sag [3]. Fortunately, the reactive power supplied by devices such as inverters can be controlled to be independent of line voltage as long as the production is below the maximum possible for the given line voltage [14].

Industrial complexes are already capitalizing on this dual capability of DER when they utilize VSDs to not only realize energy savings but also improve consumption PF [30]. Non-unity PFs result in increased current flow, but none for which 
a typical residential customer who is billed for active power consumption sees additional charge [10]. Rather, the only entities with a keen interest in maintaining an adequately high consumption PF are commercial customers who get penalized if they fail to comply with the utility's PF standards. To avoid such charges, commercial customers can employ a variety of solutions, including reactive power compensation from motors equipped with AFE VSDs. Forthcoming changes to IEEE 1547 will extend the application of the latter solution to the entire distribution grid. This approach to distribution-level PF correction is the heart of this research.

A cost summary of the highlighted solutions can be seen in Figure 2.2 [3]. Notably, the proposed solution for dynamic, distribution-level PF correction would not replace low-cost capacitor banks or other existing solutions. Rather, it would work in concert with the legacy assets shown in Figure 2.2 to provide greater flexibility to utilities trying to retain reliability while juggling load growth and a greening grid. Disregarding legality, depreciation, and controls concerns related to third party voltage regulation, the economics of any competitive DER-based voltage regulation solution should fall somewhere in the neighborhood of the costs highlighted in the figure. 


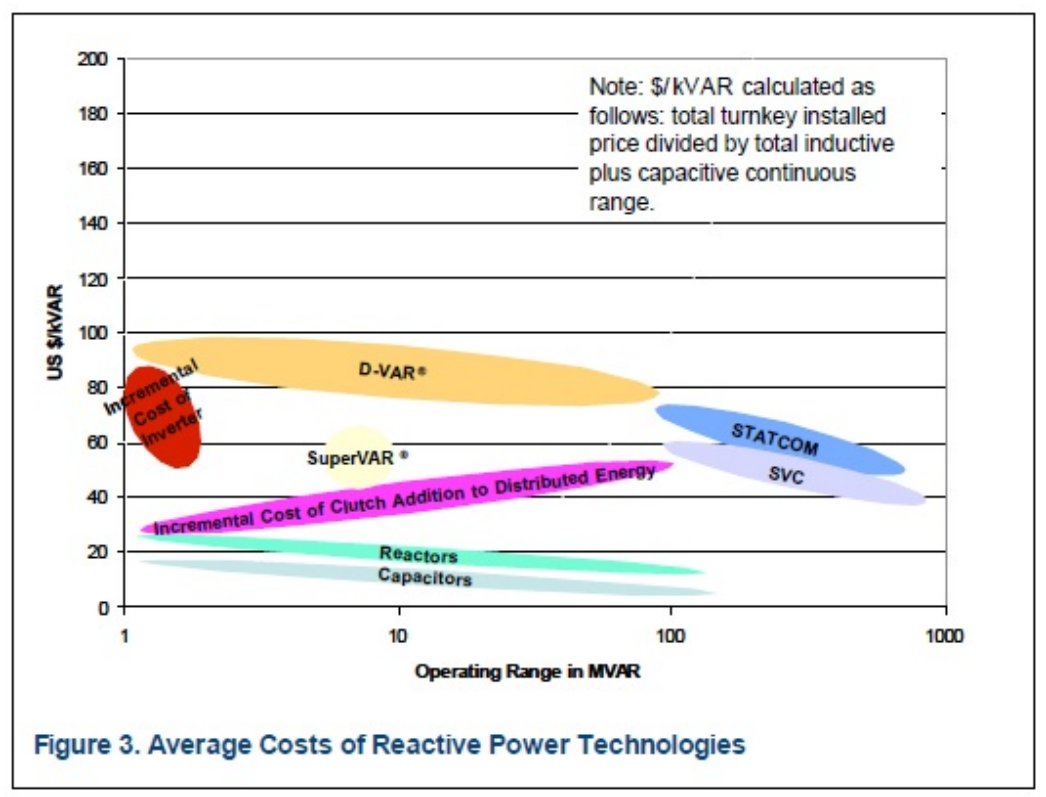

Figure 2.2: Per unit costs of various voltage regulation devices utilized by electric utilities according to Oak Ridge National Lab [3].

\subsection{Variable Speed Drives}

The chief goal of a VSD is to increase the energy efficiency of motor-driven loads by controlling the motor's speed. To accomplish this goal, a VSD adjusts the frequency of the line input to the motor [31]. A motor's synchronous speed $\left(N_{s}\right)$, or the rotational speed of its stator, is a function of the line input frequency $(f)$ and number of magnetic poles $(n)$ [31]. The stator is the stationary part of a motor; it is also the source of the electromagnetic flux (i.e. changing magnetic field) that induces an opposing current in the rotor, or rotating part of a motor [32]. The rotor accelerates until its torque equals that of the applied torque (i.e. the load) [32]. This torque is a function of slip $(s)$, among other factors [32]. Slip is the difference between the rotational speed of the rotor $(N)$ and $N_{s}$ [32]. By changing $N_{s}$, a VSD consequently changes $s$, which then adjusts the reactionary torque $(T)$ and thus power delivered $(P)$ [32]. Equations 2.4-2.7 define these relationships between $f, n, s, N, N_{s}, T$ and 
$P[32]$.

$$
\begin{gathered}
N_{s}=120 \times \frac{f}{n} \\
s=\frac{N_{s}-N}{N_{s}} \\
T \propto\left(s, N_{s}\right) \\
P \propto(T, N)
\end{gathered}
$$

A VSD includes three main components: a power converter, a DC bus, and a frequency converter [18], [33]. Beyond the DC bus, a sinusoidal voltage waveform must be recreated as input to the motor [33]. A typical approach for reconstructing this waveform is called Pulse Width Modulation, which utilizes fast switching of solid state, semiconductor components like Insulated Gate Bipolar Transistors (IGBTs) [18]. These switches lose negligible power during their operation, and have the ability to create extremely smooth waveforms [31]. The resulting voltage output is proportional to frequency, which adjusts motor speed as previously described [33].

An AFE VSD is a specific type of VSD that can operate bi-directionally, meaning it has the ability to feed power back to the grid. The power converter section of this type of drive utilizes the same power electronic components found in the frequency converter section of a traditional VSD to decrease harmonics (i.e. nonsinusoidal waveforms) and enable two-way flow. Due to the presence of these more advanced solid state components, a higher price tag typically accompanies an AFE VSD. Appropriate applications for this type of drive include craning and elevating, activities that produce braking power which could be regenerated [30].

As of the most recently published study (2002), VSDs represent $9 \%$ of total drive applications in the US despite their potential to contribute to $62-104$ billion 
kWhs per year of energy savings from the adoption of more efficient motor systems [11]. Motor driven equipment accounts for up to $61 \%$ of US electricity consumption in the industrial sector, $25 \%$ of which is attributed to pumping loads [11]. As the largest single contributor to motor loads, pumping is a prime candidate for VSD technology.

\subsection{Pump Theory}

An introduction to pump theory will identify the potential energy savings offered by a VSD. The main objective of a pumping system is the transfer of liquid to a specified destination [33]. To meet this objective, a pump must produce pressure to induce flow. This pressure, often referred to as "head," can be categorized into two types: static and friction [33]. Static head relates to the maximum height that a pump can deliver [33]. The friction losses associated with that liquid transfer are collectively referred to as friction head [33]. A system curve defines the unique combination of static and friction heads associated with a pumping scheme [33].

The pump itself can be characterized into two basic types: rotodynamic and positive displacement (PD) [33]. Pressure head on a rotodynamic pump is generated by a rotating impeller whose peripheral speed is proportional to shaft speed [33]. Alternatively, pressure head for a PD pump, like one that utilizes a piston driven by a camshaft, can be independent of shaft speed [33]. It follows that these pumps' respective performance curves, which define their head versus flow relationships at a specific impeller speed, look starkly different. The performance curve for a rotodynamic pump shows a clearly dependent relationship between flow and head; whereas, the flow associated with a PD pump is nearly independent of head [33]. A fixed speed (FS) drive always activates the pump at one impeller speed, which means the 
pump operates according to a single performance curve; whereas variable speed (VS) operation enables transition between performance curves.

Energy savings are typically maximized when a VSD is applied to a rotodynamic (e.g. centrifugal) pump since the power demanded by that type of pump is proportional to the cube of its impeller speed according to the Affinity Laws [34]. The Affinity Laws are equations governing the relationships between shaft speed and 1) volumetric flow rate 2) pressure head and 3) power given a constant impeller diameter [31]. The Affinity Laws and their equivalent mathematical expressions are enumerated in Equations 2.8-2.10.

1. Flow $(q)$ is proportional to shaft speed $(N)[34]$.

$$
\frac{q_{1}}{q_{2}}=\frac{N_{1}}{N_{2}}
$$

2. Pressure head $(H)$ is proportional to the square of $N$ [34].

$$
\frac{H_{1}}{H_{2}}=\left(\frac{N_{1}}{N_{2}}\right)^{2}
$$

3. Power $(P)$ is proportional to the cube of $N[34]$.

$$
\frac{P_{1}}{P_{2}}=\left(\frac{N_{1}}{N_{2}}\right)^{3}
$$

The intersection of a pump's performance curve and a specific system curve determines the operation of that pump under the given scheme [31]. Together with the pump efficiency, these parameters define the brake horsepower (BHP), or mechanical power, required by the pump [35]. Ideally, a pump functions at its Best Efficiency Point (BEP), or the point at which the pump's efficiency is optimized [31]. If a system curve is comprised solely of friction head then any shift in flow allows the operating point to follow a line of constant pump efficiency [31]. In this case, the Affinity Laws 
are obeyed and a VSD can save tremendous energy. However, when the system curve includes static head, as does the one in Figure 2.3, the same shift in flow results in a decrease in pump efficiency; in other words, the operating point intersects lines of progressively lower pump efficiency as flow decreases [31]. Consequently, any power savings derived from using a VSD must compete with the extra power required to operate a less efficient pump. This concept is illustrated in Figure 2.3, which displays a decrease in pump efficiency as the operating point on the system curve moves closer to the origin.

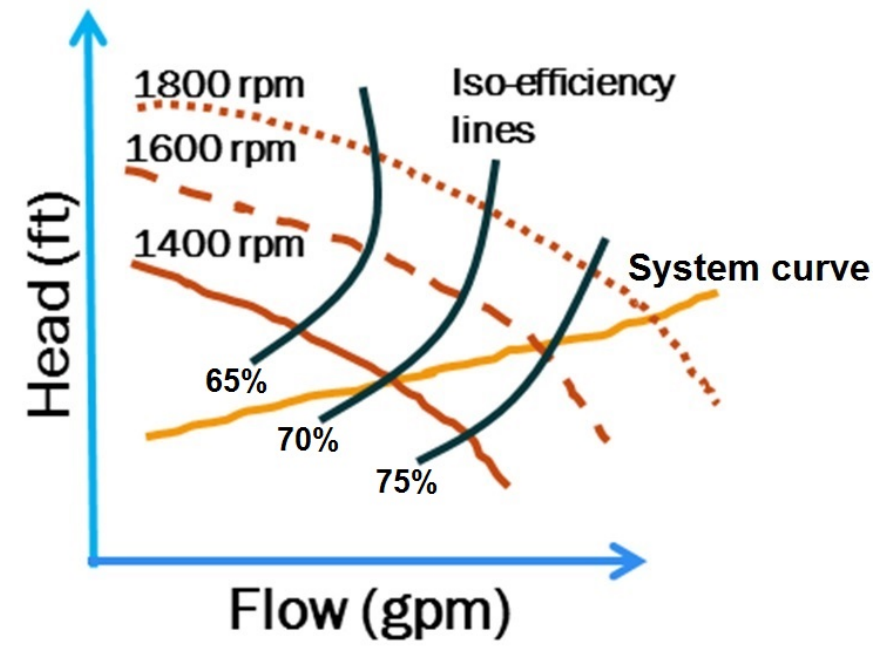

Figure 2.3: Reduction of friction head competes with a lower pump efficiency for system curves dominated by static head.

VSDs can still save energy when static head contributes to the system curve. The alternative for controlling volumetric flow rate is typically the use of a throttling valve, which achieves the desired flow rate but causes an unnecessarily high system pressure, a result of following a certain performance curve (at a specific impeller speed) rather than the system curve [34]. Utilization of a VSD reduces the additional friction head associated with this inflated system pressure [34]. 
The choice of a centrifugal sewage pump as the target for this research is predicated on the theory outlined above. As a distributed, motored, rotodynamic machine, this type of pump could operate more efficiently if variably driven. Consequently, a portion of a VSD's capacity could go unused during certain times of day when active power demand is low. It is during these low-load periods that the VSD could provide PF correction to the local grid while maintaining an adequately high $\mathrm{PF}$ for the sewage pump. Given the extra cost typically associated with an AFE VSD, the pending question to be tackled is: how much PF correction could the VSD actually provide and at what price per unit of reactive power supplied would the third party owner of the sewage pump be willing to invest in a VSD capable of providing grid support? 


\section{Chapter 3}

\section{Computational Approach \& Analysis}

\subsection{Data Utilized}

Datasets are obtained from two sources: Austin Water Utility (AWU) and the Pecan Street. AWU is the municipally owned water treatment and distribution entity for the City of Austin [36]. In total, the utility supplies water to nearly 890,000 residential, commercial and industrial consumers [36]. Pecan Street is the flagship effort of Pecan Street Inc., a research and development organization focused on advancing understanding and solutions addressing utility system reliability, climate change, renewable energy integration, and customer needs and preferences [37]. The demonstration has produced an enormous dataset of electricity and water usage patterns at intervals as small as one minute for over 735 homes, approximately 180 of which include rooftop PV systems [5]. Only a portion of the homes with PV systems are used in this analysis.

The original Pecan Street dataset (before scrubbing) includes hourly-averaged demand and PV generation for a load pocket of 86 homes in the Mueller Division, one of the communities that Pecan Street monitors. The data span May 2012 to April 2013, or one full year. These homes are connected to the same single-phase line, so their consumption is aggregated and treated as a load pocket with one point of common coupling (PCC) to the distribution lateral [5]. PF is measured at the lateral service entrance per Figure 3.1 assuming that the VSD and load pocket coincide at this location. Thus, the distance between the VSD and load pocket is neglected, as 
are the distances between the individual homes that contribute to the load pocket. However, these factors are relevant and worth including for future work.

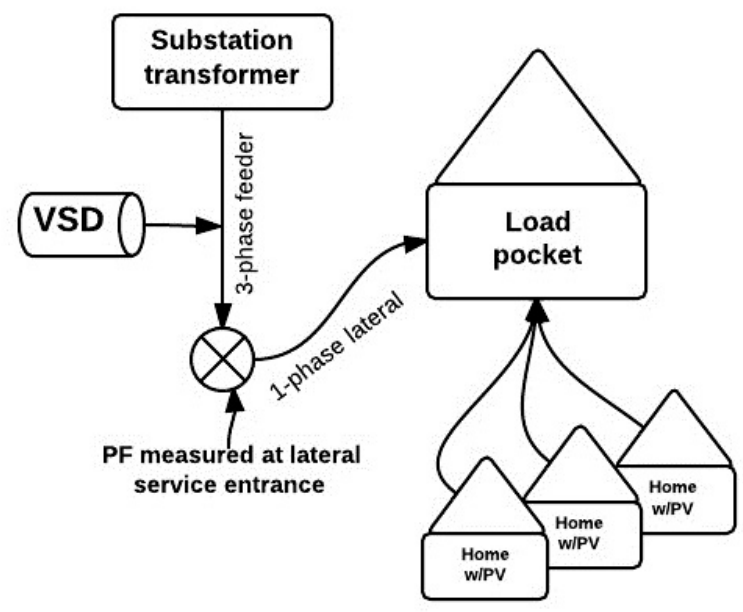

Figure 3.1: $\mathrm{PF}$ is measured at the lateral service entrance assuming that the VSD and load pocket coincide at this location.

AWU data are not as comprehensive as AE data, as reliable time-series operating records at the water utility are limited. Therefore, this analysis relies predominantly on data derived from an AWU report (circa 1997) that summarizes a study performed by the City of Austin upon the city's designation as an "Energy Smart City." The report explores the economic viability of applying VSDs to a number of pumps across AWU's service territory, including one at the Rattan Creek Lift Station (Rattan Creek).

Rattan Creek was constructed in 1987 in Northwest Austin and includes three centrifugal pumps (model 6NHTAVM) manufactured by Cornell Pump Co. Each pump has a rated capacity of $30 \mathrm{~kW}$ when using a 10.5 inch diameter impeller operated at a maximum of 1780 rotations per minute (RPM) [38]. Although three pumps exist at Rattan Creek, this analysis considers the operation of only one pump. This single pump simplification is predicated on the fact that one $30 \mathrm{~kW}$ pump is over 
three times oversized for the station's maximum load. Oversizing sewage pumps is a common practice among water utilities to ensure adequate capacity in case of increased demand resulting from environmental factors like rain storms [39].

Operating data on the chosen sewage pump were obtained empirically by monitoring it on two separate occasions: 1) over the course of one month (from August 9 to September 9,1996) to obtain incoming flowrates and their durations for the purpose of constructing a diurnal curve and 2) over the course of one day (on July 16,1996) to obtain pressures and outgoing flowrates for the purpose of constructing a system curve [38]. Notably, mostly dry weather was observed during the inflow monitoring period yet the study extrapolated annual operating requirements from this homogeneous snapshot [38]. Consequently, seasonal demand variations due to wet weather conditions were neglected.

Table 3.1 summarizes the array of data from Pecan Street and AWU including their sources, vintages, and storage methods.

Table 3.1: Integral to the research are datasets from AWU and Pecan Street

\begin{tabular}{|l|l|l|l|}
\hline Source & Vintage & $\begin{array}{l}\text { Storage } \\
\text { Medium }\end{array}$ & Data \\
\hline AWU & 1997 & $\begin{array}{l}\text { Hard-copy } \\
\text { report }\end{array}$ & $\begin{array}{l}\text { Diurnal flow pattern, sys- } \\
\text { tem/efficiency curves, FS \& } \\
\text { VS electricity consumption }\end{array}$ \\
\hline AE & 2013 & PDF & $\begin{array}{l}\text { FS electricity consumption } \\
\text { \& PF measurements }\end{array}$ \\
\hline Pecan Street & $2012 / 13$ & $\begin{array}{l}\text { Character Sep- } \\
\text { arated Values } \\
\text { (CSV) }\end{array}$ & $\begin{array}{l}\text { Grid demand, PV genera- } \\
\text { tion }\end{array}$ \\
\hline Pecan Street & N/A & Microsoft Excel & PV system capacities \\
\hline
\end{tabular}




\section{$3.2 \quad$ Structure \& Programs Employed}

The computational simulation is constructed in MATLAB and Simulink. The simulation is split into three main components whose results are combined to achieve the final conclusions. These components include:

1. Calculating the hourly active power requirements of the sewage pump when operated using a VSD and allocating the "headroom," or leftover capacity, of the drive to provision of reactive power.

2. Determining the hourly reactive power demand of the aggregated load pocket to maintain $\mathrm{PF}$ at 0.95 and calculating the extent to which reactive power from the VSD can fill that gap.

3. Determining the utility payment required (in addition to energy and demand savings) to ensure AWU achieves full payback of an AFE VSD investment in a specified number of months.

\subsection{Data Cleanup}

Before building algorithms to accomplish the enumerated tasks, the Pecan Street data are scrubbed. Due to the presence of unique home characteristics (e.g. differing PV system sizes) and varying time-series lengths per month, the scrubbing process is performed on a by-home, by-month basis. To facilitate this cleanup procedure, the structure array storage method - which can handle various types and sizes of data by separating them into different parts of the structure and assigning meta-labels to each part - is utilized.

The original size of the imported array is $12 \times 86$, representing 12 months of the year for 86 unique homes. Data for each home is maintained in time-series, ascending 
order before compilation. Of the 86 homes, 63 survive the cleanup procedure, meaning 23 of the homes in the original dataset are removed due to the enumerated integrity issues.

1. Zero or negative consumption.

2. PV generation in excess of $115 \%$ of PV system capacity. A $15 \%$ cushion to PV system capacity is added to account for "cloud-focused" solar irradiation [40].

3. Grid demand in excess of $15 \mathrm{~kW}[5]$.

4. Zero grid demand, which necessitates the unlikely scenario that PV generation exactly offset home consumption.

5. Negative PV generation outside the limits of inverter losses. Residual draw is assumed to be $3 \%$ of PV system capacity, which equates to $97 \%$ efficiency for an appropriately sized inverter [41].

Instead of rectifying these issues, the homes possessing the issues are removed. For example, negative PV generation (i.e. losses) within the prescribed limits is reassigned as grid demand. Homes with losses outside of those limits, on the other hand, are tagged for discard from the scrubbed dataset.

Further, any missing values on the edges of the time-series are plugged with assumed values to ensure continuity. These filler values are calculated by averaging the first and last data points in the series. If more than one value is missing, the average is updated using the most recently calculated filler value. As an added caution, consumption data are calculated per Equation 3.1 as opposed to directly acquiring them from Pecan Street. This approach ensures that consumption values $\left(C_{h}\right)$ never 
disagree with their contributing components, grid demand $\left(P_{h}\right)$ and PV generation $\left(P V_{h}\right)$.

$$
C_{h}=P_{h}+P V_{h}
$$

\subsection{Load Pocket Characterization}

With a feasible dataset established, the analysis turns to adjusting the PV generation of individual homes to represent varying levels of penetration in the load pocket. PV penetration is originally defined, for the purpose of initializing the analysis, as the percentage of homes with PV systems - regardless of installation size - out of all homes in the sample size. Since each of the 63 homes in the scrubbed dataset includes a PV system, an artificial penetration value is constructed by reassigning PV generation to active power demand from the grid for an appropriate number of homes for the desired penetration percentage. PV penetration is varied from $5 \%$ to $30 \%$ to understand the sensitivity of PF to increasing PV penetration. Random homes are initially chosen for the $5 \%$ penetration case; additional homes are added to the initial set as penetration increases to its upper limit. PV penetrations above $30 \%$ are not considered because the benefit of reactive compensation diminishes beyond that threshold [42].

Subsequently, the load pocket's annual active power consumption $\left(C_{l p}\right)$, including PV generation $\left(P V_{l p}\right)$ and grid demand $\left(P_{l p}\right)$, is constructed. To accomplish this task, Equation 3.1 is applied to each hour within each month across the scrubbed set of 63 homes. Then, the aggregated monthly data are concatenated into three annual arrays. Since Pecan Street does not monitor PF, a randomized PF between 0.86 and $0.91\left(P F_{i}\right)$ is applied to $C_{l p}$ to determine the load pocket's initial reactive power 
demand $\left(Q_{d}\right)$ [43]. The quantity of reactive power allowable $\left(Q_{a}\right)$ on the distribution feeder is then determined by applying a randomized PF between 0.95 and $1.0\left(P F_{f}\right)$ to $P_{l p}[10]$. Regardless of the presence of PV generation, local reactive power compensation would be required in this scenario. However, since PV generation from a "dumb" inverter only offsets active power demand, the initial PF of the load pocket decreases even further below $P F_{i}$. The unmet gap $\left(Q_{g a p}\right)$ between $Q_{d}$ and $Q_{a}$ must be supplied from an alternative, local source. In this case, that local source is the VSD. Equations 3.2-3.5 describe the series of calculations to determine $Q_{g a p}$.

$$
\begin{aligned}
C_{l p} & =\sum_{1}^{63}\left(P_{h}+P V_{h}\right) \\
Q_{d} & =P F_{i} \times C_{l p} \\
Q_{a} & =P F_{f} \times P_{l p} \\
Q_{g a p} & =Q_{d}-Q_{a}
\end{aligned}
$$

\subsection{Data Digitization and Dynamic Model Creation}

Determining the active power demand of the selected pump is essential to understanding the VSD's PF correction capability since only the drive's headroom is used for reactive power compensation. Demand response of active power in favor of PF correction is not considered.

Unlike the AWU study that maintained constant sewage demand throughout the year, this analysis assumes seasonal variations in sewage demand based on external factors like rainfall. Specifically, monthly scaling factors $\left(S F_{m}\right)$ are applied to the diurnal curve. These monthly scaling factors are ratios of the pump's monthly FS energy consumption $\left(C_{F S}\right)$ according to $2013 \mathrm{AE}$ electricity bills using August as the 
base month. Since a FS pump always activates at the same speed, variations in FS energy consumption are solely attributed to an increase in the magnitude of incoming flowrates.

An annual scaling factor $\left(S F_{a}\right)$ representing demand inflation from 1997 to 2013 is also applied to the diurnal curve. Since the average of the $S F_{m}$ values is greater than one, $S F_{a}$ is adjusted $\left(S F_{a a}\right)$ such that the combined effect of monthly and annual adjustments equals the unadjusted demand increase from 1997 to 2013. Equations 3.6-3.9 outline this procedure, which assumes that intrinsic factors like the degradation of pump efficiency do not contribute to the differences in FS energy consumption observed.

$$
\begin{aligned}
S F_{m} & =\frac{C_{F S, \text { month }}}{C_{F S, A u g}} \\
\overline{S F}_{m} & =1.07>1 \\
S F_{a} & =\frac{C_{F S, 2013}}{C_{F S, 1997}}=1.7 \\
S F_{a a} & =S F_{a} \div \overline{S F}_{m}=1.59
\end{aligned}
$$

The diurnal curve provided in the AWU report is digitally reconstructed by extracting data points at every half-hour and using piecewise linear interpolation to fill the gaps between empirical observations. Linear interpolation is a curve-fitting method that utilizes linear polynomials $(y=m x+b)$ as the estimating mechanism between any two known data points or "knots" [44]. The piecewise method is chosen to avoid interpolating over the entire range of 48 observations, which would have resulted in a 47th degree polynomial fit [44]. In general, if $n$ data points exist, the degree of the polynomial fit is $n-1$ [44]. Figure 3.2 shows an overlay of the original diurnal curve and the piecewise fit. 


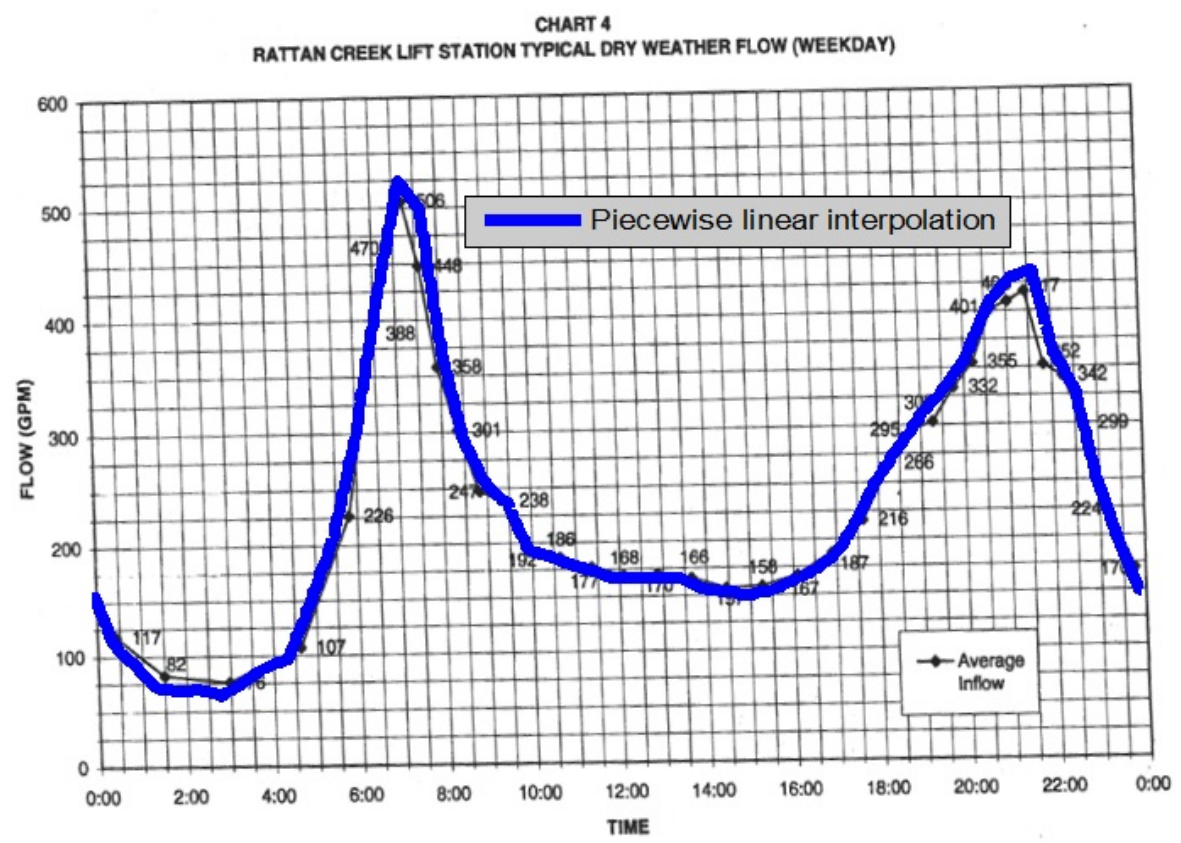

Figure 3.2: Recreation of diurnal curve using piecewise linear interpolation

The digitally reconstructed diurnal curve is an essential input to the Simulink model that emulates VS operation of the sewage pump in conjunction with a wet well. A wet well is a basin into which sewage water flows [45] as illustrated in Figure 3.3. Only until the water level reaches a certain height in the wet well does the pump start sucking from the bottom of the basin [45]. The pump then shuts down when the water level reduces to a different prescribed height [45]. Typically, two pumps operate at a lift station even though one could handle the load independently, as this analysis assumes. In the dual-pump scenario, one pump acts as the "lead" and the other acts as the "lag" with an alternator switching their roles at each new cycle [45]. Trigger levels differ for the pumps, and only after both triggers are activated do the pumps operate in parallel [46]. Either a set of mechanical float switches or an electrical transducer activates the pumps when the trigger levels are reached [45]. 


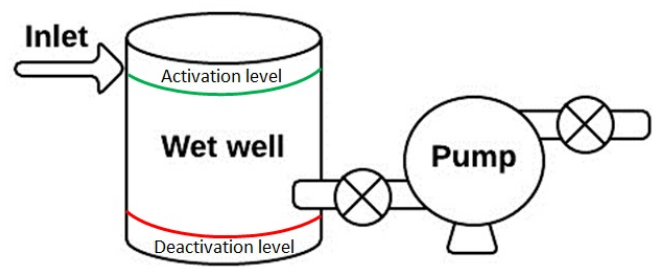

Figure 3.3: Sewage pumps operate in conjunction with a wet well.

The Simulink model is governed by Equation 3.7 where $h$ is the height of sewage water in feet $(f t), A$ is the cross-sectional area of the wet well in $f t^{2}$, and $\dot{q}$ is the volumetric flowrate of sewage water into or out of the wet well in gallons per minute $(G P M)$. Although the solution of Equation 3.10 is typically non-linear due to the dependence of the outgoing flowrate on $h$, this model assumes a linear solution due to a discrete change $(+/-G P M)$ in outgoing flowrate as a function of incoming flowrate per simulation step.

$$
\frac{d h}{d t}=\frac{1}{A}\left(\dot{q}_{\text {in }}-\dot{q}_{\text {out }}\right)
$$

In the model, the pump is initially off, which means the outgoing flowrate is zero. After subtracting this outgoing flowrate from the incoming flowrate for that time step, the resulting net flowrate is divided by the cross-sectional area $A$. This value is then integrated to obtain the current water height, $h$. When the water in the wet well reaches the activation height, the pump is turned on. If the incoming flowrate is less than 300 gallons per minute (GPM), the pump is forced to discharge at 300 GPM so that the check valve, which prevents backflow into the pump, operates properly [46]. Otherwise, the pump discharges at the incoming flowrate. The net flowrate is then recalculated, and the height is updated. If the incoming flowrate increases while the 
wet well is full, then the pump ramps up to the current incoming flowrate. The pump shuts down once the water in the wet well reaches the deactivation height.

The simulation includes 1440 fixed time steps representing the 1440 minutes per 24 hour period. The diurnal curve is varied on a monthly basis using $S F_{m}$ in combination with $S F_{a a}$; as a result, $q_{o u t}$ is a function of these scaling factors. The water height and outgoing flowrates are determined at each time step and used to calculate the minute-by-minute mechanical pumping power $\left(k W_{m}\right)$ demand $\left(k W_{m}\right)$ is calculated per Equation 3.12. This calculation requires the water pressure (i.e. "head" $H$ ) and pump efficiency $\left(\eta_{p}\right)$ associated with each outgoing flowrate, which are determined using the pump's system and efficiency curves, respectively. The functional relationship between $\dot{q}_{\text {out }}$ and $H$ is defined by the system curve because the VSD allows the pump to exactly match operational demand.

$$
k W_{m}=0.746\left(\frac{\dot{q}_{\text {out }} \times H}{3956 \times \eta_{p}}\right)
$$

The system and efficiency curves used to determine $H$ and $\eta_{p}$, respectively, are digital recreations of those found in the AWU report. The internal MATLAB function polyfit is used to develop these digital versions of the curves, which are quadratic functions of outgoing flowrate. The coefficient of determination $\left(\mathrm{R}^{2}\right)$ values for the curves are both close to unity ( 0.97 for the efficiency curve and 0.99 for the system curve), indicating good fits. Figure 3.4 shows the original curves with the polyfit curves overlaid. 


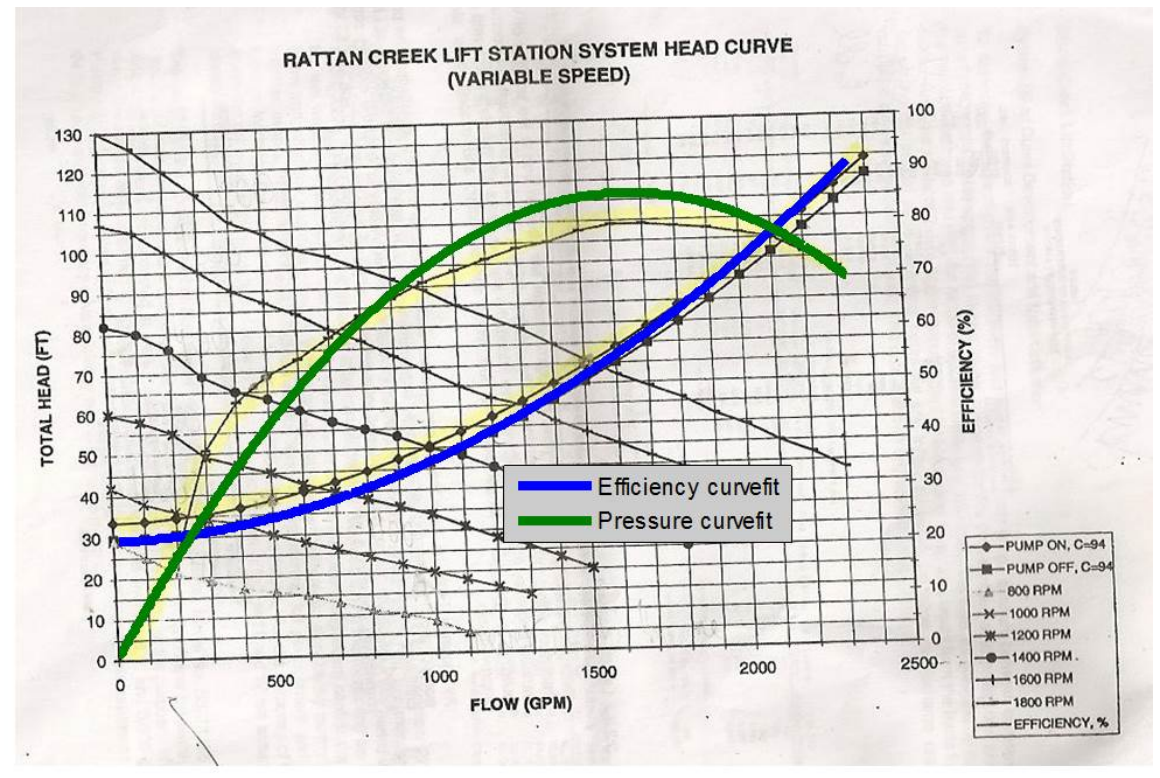

Figure 3.4: Digital recreation of system and efficiency curves using polyfit yields $R^{2}$ values of 0.99 and 0.97 , respectively.

\subsection{Introduction of Electrical Efficiency}

The previous procedure outlines determination of the mechanical power demand of the sewage pump. Only pump efficiency and underlying laws of fluid dynamics contribute to the calculation. Upon the pump's connection to a VSD, which controls input power from the motor and is the device capable of reactive power compensation, electrical efficiency must be included. Since the pump currently utilizes a FS drive, the choice of a VSD for this analysis is only limited by the requirements that the drive 1) include an AFE and 2) be sized to match the pump's maximum capacity $(30 \mathrm{~kW})$. With these stipulations in mind, the Emerson SP3403 Uni-Drive is selected. The motor to which the VSD is connected is arbitrary; only the efficiency of the motor is considered. A visual of the combined (mechanical and electrical) system setup is shown in Figure 3.5. 


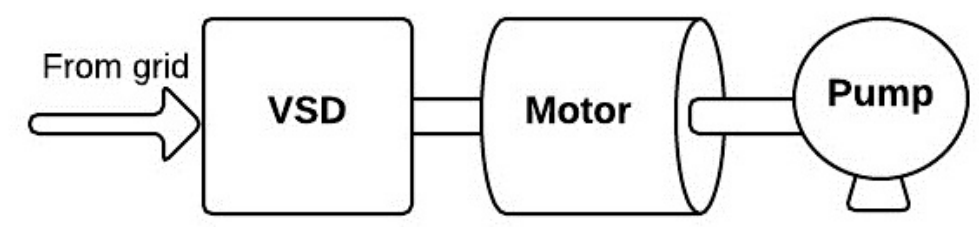

Figure 3.5: The pump system includes mechanical and electrical components.

By applying a combined (VSD and motor) electrical efficiency to the mechanical power $\left(k W_{m}\right)$, the pump's power demand from the grid is determined. A range of combined electrical efficiencies are applied to $k W_{m}$ to understand the impact of this parameter on the payback period of the VSD investment. Further, the effect of partial loading on the electrical efficiency of a VSD and/or motor is not well understood; thus, a range of values aligns with this uncertainty. In particular, the Advanced Manufacturing Office of the U.S. Department of Energy (DOE) Office of Energy Efficiency and Renewable Energy (EERE) published a guide assessing the efficiency variability of a VSD and defines a lower limit for the value far below that noted in a 2008 study published by researchers from California Polytechnic Institute (Cal Poly). In the EERE guide, VSD efficiency (for a $22 \mathrm{~kW}$ drive) can drop as low as $88 \%$ for motor loading in the teens, as seen in Table 3.3 [1]. In contrast, the Cal Poly study indicates a lower threshold for VSD efficiency of approximately $95 \%$ regardless of motor loading [47].

Table 3.2: VSD efficiency degradation under partial loading according to EERE [1].

\begin{tabular}{|l|c|c|c|c|c|c|c|}
\hline \multirow{2}{*}{$\begin{array}{l}\text { VSD } \\
\text { Rating }\end{array}$} & \multicolumn{6}{|c|}{ Efficiency (\%) } \\
\cline { 2 - 8 } & \multicolumn{1}{|c|}{ Load, \% of VSD Rated Output } \\
\cline { 2 - 8 } & $\mathbf{1 . 6}$ & $\mathbf{1 2 . 5}$ & $\mathbf{2 5}$ & $\mathbf{4 2}$ & $\mathbf{5 0}$ & $\mathbf{7 5}$ & $\mathbf{1 0 0}$ \\
\hline $22 \mathrm{~kW}$ & 50 & 88 & 93 & 95 & 95 & 96 & 97 \\
\hline $37 \mathrm{~kW}$ & 46 & 86 & 92 & 95 & 95 & 96 & 97 \\
\hline
\end{tabular}

Assuming the same motor efficiency as that used in the AWU report (94\%), 
the average electrical power required by the sewage pump over the course of one year is approximately $15 \%$ of its full capacity [38]. Using the $88 \%$ value from EERE and the max value (98\%) noted by Cal Poly as upper and lower limits of VSD efficiency, respectively, this analysis evaluates power requirements using combined electrical efficiencies $\left(\eta_{e}\right)$ between $82 \%$ and $92 \%$. The adapted equation for hourly pumping power demand $\left(P_{p}\right)$ is shown in Equation 3.12. Minute-wise energy contributions over the course of one hour are combined to determine the equivalent power demand of the pump if it had been operating at a constant level for the entirety of the hour.

$$
P_{p}=\sum_{1}^{60} \frac{1}{60}\left[0.746\left(\frac{\dot{q}_{\text {out }} \times H}{3956 \times \eta_{p} \times \eta_{e}}\right)\right]
$$

\subsection{Dynamic Model Calibration}

The Simulink model is calibrated using the annual VS energy consumption specified in the AWU report. Although this AWU value is an extrapolation, it provides a reasonable benchmark to assess the model's results. Initial model output using a minimum outflow requirement of $300 \mathrm{GPM}$ yields a $28 \%$ overshoot of the report value. Based on insight from the company Specific Energy, this error is likely due to the detrimentally low mechanical efficiencies that result from operating the pump at such low flowrates. Specific Energy's empirical results, collected from trials at numerous water utilities across the country, suggest that optimal operation of a VSD applied to a pumping system should occur somewhere in the range of $75 \%$ of nominal grid frequency [48]. For the chosen pump, that range corresponds to approximately $45 \mathrm{~Hz}$ or $1400 \mathrm{RPM}$. At this speed, the pump intersects the system curve at

approximately 1000 GPM, a value that exceeds any incoming flowrate throughout the year [38]. Consequently, this minimum flowrate forces pump activation exclusively at 
1000 GPM, and the net flowrate $\left(\dot{q}_{\text {in }}-\dot{q}_{\text {out }}\right)$ becomes a function of incoming flowrate alone. Adjusting the Simulink model to reflect this new minimum flowrate yields better alignment with the 1997 consumption value. Specifically, the results agree within a $11 \%$ error for a combined electrical efficiency of $92 \%$. Given the uncertainty surrounding the 1997 methodology for determining the pump's VS energy consumption, this error is deemed acceptable.

\subsection{Reactive Power Compensation From the VSD}

The capacity of the VSD available for reactive power compensation is a function of this calibrated pumping power demand. The headroom is determined using Equation 3.13, where $P_{p}$ is the active power load on the VSD and $S_{V S D}$ is the full capacity of the drive $(30 \mathrm{kVA})$. Since the drive is three-phase and the load pocket is connected to a single phase line, the resulting headroom is divided by three, assuming balanced three-phase loading in the distribution network. $Q_{V S D}$ represents this adjusted headroom, which is used to supply reactive power to the local grid.

$$
Q_{V S D}=\frac{\sqrt{S_{V S D}^{2}-P_{l p}^{2}}}{3}
$$

During certain hours of the day, however, pumping demand is zero and Equation 3.10 does not apply. Contrary to the initial assumption that the full capacity of the drive could be used for reactive power compensation during these no-load periods, some active power is still necessary from the grid to 1 ) overcome inversion losses (i.e. operate the power electronics in the front end of the drive) and 2) regulate the voltage of the drive's DC bus [49]. Typically, active power to overcome inversion losses is supplied by a portion of the electricity already demanded from the grid or generated by the renewable resource [49]. In this case, that power must be drawn from the grid. 
In addition, it must be in excess of inversion losses to ensure adequate charging of the DC bus [49]. One study recommends that the "active power command," or the portion of any control logic that would allow for DC charging, be set to $-K \times P_{\text {losses }}$ where $K>1$ [49]. A larger value of $\mathrm{K}$ allows for faster re-charging and response times in the DC bus [49]. In this analysis, $K$ is chosen to be 3.0, the approximate value as that used in the study, and the active power draw from the grid is defined by Equations 3.14 and 3.15 [49]. Inversion losses are assumed to be $3 \%$ of the nameplate capacity $(S)$ of the drive [41].

$$
\begin{aligned}
P_{p} & =3 \times P_{\text {losses }} \\
& =3 \times\left(.03 \times S_{V S D}\right)
\end{aligned}
$$

The reactive power available from the $\operatorname{VSD}\left(Q_{V S D}\right)$ is then adjusted to account for the load pocket's unmet gap $\left(Q_{\text {gap }}\right)$ to determine the appropriate local supply $\left(Q_{l s}\right)$.

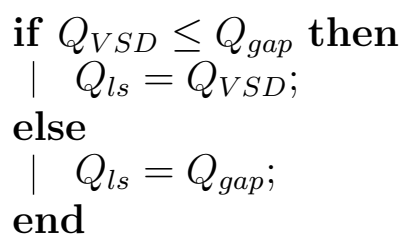

Equation 3.16 describes the load pocket's old PF $\left(P F_{\text {old }}\right)$ before $Q_{l s}$ is utilized. Equations 3.17-3.18 describe the series of calculations to determine the load pocket's new $\mathrm{PF}\left(P F_{\text {new }}\right)$ considering the adjusted reactive power demand from the distribution grid $\left(Q_{d a}\right)$. 


$$
\begin{aligned}
P F_{\text {old }} & =\frac{P_{l p}}{\sqrt{P_{l p}^{2}+Q_{d}^{2}}} \\
Q_{d a} & =Q_{d}-Q_{l s} \\
P F_{\text {new }} & =\frac{P_{l p}}{\sqrt{P_{l p}^{2}+Q_{d a}^{2}}}
\end{aligned}
$$

\subsection{Energy and Demand Savings From Using a VSD}

Determining the PF improvement $\left(\frac{\left(P F_{n e w}-P F_{\text {old }}\right.}{P_{\text {old }}}\right)$ offered by the VSD is one of two research goals. The other goal, which entails determining the utility payment to the VSD owner, requires calculating the energy and demand savings realized by switching the pump to VS operation. These savings are calculated by applying the Austin Energy (AE) rate schedule to the FS and VS energy consumption of the pump, and comparing the results.

The AE rate schedule tabulates charges by season, customer, demand, and voltage. It is important for $\mathrm{AE}$ to group customers by similar-use characteristics because customer service needs and electrical consumption can vary substantially among groups [2]. Seasons are winter or summer, where winter spans June through September and summer spans October through May [2]. AWU is a commercial (versus industrial or residential) customer, and each of its sewage stations receives separate AE bills. Depending on the peak power demand of the chosen pump, it could fall in one of two demand classes: $P<10 \mathrm{~kW}$ (refer to Figure 4.1 ) or $10 \mathrm{~kW} \leq P \leq 50$ $\mathrm{kW}$. Peak power demand is the highest average power demand over the course of 15 minutes [50]. Unless a single value of power demand is sustained for 15 minutes, the maximum value of power demand for the billing period according to AE's definition will not necessarily equal the actual peak power demand. Finally, a customer can 
belong to one of two voltage categories: primary or secondary. The primary voltage category applies to high voltage lines (i.e. MW-order loads) extending directly from the substation; whereas the secondary voltage category applies to low voltage lines (i.e. $\mathrm{kW}$-order loads) extending from step-down transformers [2]. AWU belongs to the secondary voltage category.

AE invoices customers in one of three ways: 1) a flat charge on the entire bill (Customer Charge, $C$ ) 2) a charge per unit of peak power (Demand Charge, $D$ and Delivery Charge, $D Y$ ) and 3) a charge per unit of energy (Electricity Charge, $E$ and Fuel Charge, $F)[2]$. Notably, the Regulatory Charge $(R)$, or cost recovery for the expansion and upkeep of the transmission grid, is the only charge that applies to either peak power demand or energy consumption depending on demand class [2]. Summer charges are typically higher than winter charges due to predominantly air conditioning load, which forces AE to utilize more expensive generators during that season. Table 3.3 summarizes the rates applicable to AWU for the pump at Rattan Creek.

Table 3.3: Rattan Creek's monthly electricity bill is comprised of $E, F, D, D Y, R$ and $C$ charges that differ by demand class and season [2].

\begin{tabular}{|l|c|c|c|c|}
\hline \multirow{2}{*}{ Charge Type } & \multicolumn{3}{|c|}{$\$ / \mathbf{k W} \mathbf{\$} / \mathbf{k W h}$ or $\$ /$ customer } \\
\cline { 2 - 5 } & \multicolumn{2}{|c|}{$<\mathbf{1 0} \mathbf{k W}$} & \multicolumn{2}{c|}{$>\mathbf{1 0} \mathbf{k W}$} \\
\cline { 2 - 5 } & Summer & Winter & Summer & Winter \\
\hline Energy $(E)$ & $.06198(/ \mathrm{kWh})$ & $.04598(/ \mathrm{kWh})$ & $.02914(/ \mathrm{kWh})$ & $.02414(/ \mathrm{kWh})$ \\
\hline Fuel $(E)$ & $.0371(/ \mathrm{kWh})$ & $.0371(/ \mathrm{kWh})$ & $.0371(/ \mathrm{kWh})$ & $.0371(/ \mathrm{kWh})$ \\
\hline Demand $(D)$ & $0(/ \mathrm{kW})$ & $0(/ \mathrm{kW})$ & $6.15(/ \mathrm{kW})$ & $5.15(/ \mathrm{kW})$ \\
\hline Delivery $(D Y)$ & $0(/ \mathrm{kW})$ & $0(/ \mathrm{kW})$ & $4(/ \mathrm{kW})$ & $4(/ \mathrm{kW})$ \\
\hline Regulatory $(R)$ & $.00859(/ \mathrm{kWh})$ & $.00859(/ \mathrm{kWh})$ & $2.56(/ \mathrm{kW})$ & $2.56(/ \mathrm{kW})$ \\
\hline Customer $(C)$ & $18(/$ customer $)$ & $18(/$ customer $)$ & $25(/$ customer $)$ & $25(/$ customer $)$ \\
\hline
\end{tabular}

An important caveat to the Demand Charge is a penalty administered for low 
PF. Unlike residential customers who are only charged for active power consumption, commercial customers are subject to rates that account for reactive power demand, also [10]. Electric utilities differ in the type of PF penalties that they levy. In particular, AE scales $D$ by multiplying it by a ratio comparing the desired PF of 0.9 to a customer's actual PF as recorded during the period of peak power demand [43]. For example, if AE measured a PF of 0.7 during a peak power event then $D$ would

be multiplied by $\left(\frac{0.9}{0.7}\right)$. For customers with high values of peak power demand, this penalty can be costly. One of the capabilities of an AFE VSD is its insurance that load PF remains close to 1.0 [51]. Therefore, AFE VSDs could not only function as PF correction devices, but also eliminate PF penalties for the commercial customers who own them.

Four permutations of two seasons and two demand classes apply to the pump depending on the demand class into which it falls during a certain month. Equations 3.19 and 3.20 in combination with Table 3.3 provide a framework for calculating monthly energy and demand savings $\left(\$_{m s}\right)$, or the difference between fixed speed $\left(F S\left(\$_{A E}\right)\right)$ and variable speed $\left(V S\left(\$_{A E}\right)\right)$ expenditures. Note that the PF penalty only applies to FS power demand.

$$
\begin{aligned}
& \$_{A E}=\$_{\text {Energy }}+\$_{\text {Fuel }}+\$_{\text {Demand }} \times\left(\frac{.9}{P F}\right)+\$_{\text {Delivery }}+\$_{\text {Regulatory }}+\$_{\text {Customer }} \\
& \$_{m s}=F S\left(\$_{A E}\right)-V S\left(\$_{A E}\right)
\end{aligned}
$$

\subsection{Utility Payment}

The financial concept of "net present value" (NPV) is used to perform a payback analysis of a VSD investment given the monthly energy and demand savings it achieves per Equation 3.20. By applying a discount rate to these monthly cash flows, 
the extent to which they offset the upfront cost of the VSD is projected. The list price for the chosen VSD is $\$ 6755$ based on a supplier quote [52]. According to AWU, the City of Austin discount rate of $5 \%$ would apply to an investment in a new asset like a VSD [53]. Using these values, the NPV of the energy and demand savings per month $\left(\$_{m s p}\right)$ are calculated using Equation 3.21, where the annual discount rate $(5 \%)$ is converted to a monthly discount rate $(.42 \%)$ by dividing it by 12 , and $m$ represents the number of months that separates the cash flow from the initial investment [54].

$$
\$_{m s p}=\frac{\$_{m s}}{(1+.0042)^{m}}
$$

The cumulative NPV $\left(\$_{N P V}\right)$ is calculated by summing the monthly contributions in the chosen range $(M)$ per Equation 3.22 [54].

$$
\$_{N P V}=\sum_{1}^{M} \$_{m s p}
$$

Equations 3.23 and 3.24 are used to determine the utility payment $(\$ / k V A R)$ necessary if full payback is not achieved with energy and demand savings alone. The payment is determined by dividing the lump sum $\left(\$_{l s}\right)$, or the upfront payment necessary to achieve NPV=0, by the median reactive power offered by the VSD over the course of one year. The median value is chosen since it best represents the variety of reactive capacities offered.

$$
\begin{aligned}
\$_{l s} & =\$_{V S D}-\$_{N P V} \\
\$ / k V A R & =\frac{\$_{l s}}{Q_{\text {median }}}
\end{aligned}
$$




\section{Chapter 4}

\section{Results}

Results indicate that using a VSD as a grid device could be mutually beneficial to the commercial customer who owns the drive and the electric utility that purchases the PF correction provided. In particular, findings reveal that the payback period required to ensure a competitive per unit cost of VSD-based PF correction is acceptable even when using the drive for a inappropriate application like the Rattan Creek sewage pumping. In particular, the pump essentially reverts to FS operation due to the minimum outgoing flowrate requirement. A more detailed discussion of this observation is presented in the following section, which addresses the technical capabilities of the solution, as well as its implications on a customer's energy expenses and the electric utility's cost of grid reliability.

\subsection{Pump Operation With a VSD}

Figure 4.1 provides a 24-hour snapshot during the month of December of the pump's hourly active power demand, and the remaining capacity available for PF correction to the load pocket. Output from the dynamic model indicates activation of the pump at a single outgoing flowrate; thus, differences in active power demand are attributable to cycling frequency. Values shown in the figure are those that would be demanded if the pump operated at a constant level for the entirety of the hour displayed.

A deeper look inside this hourly profile is shown in Figure 4.2, which examines 


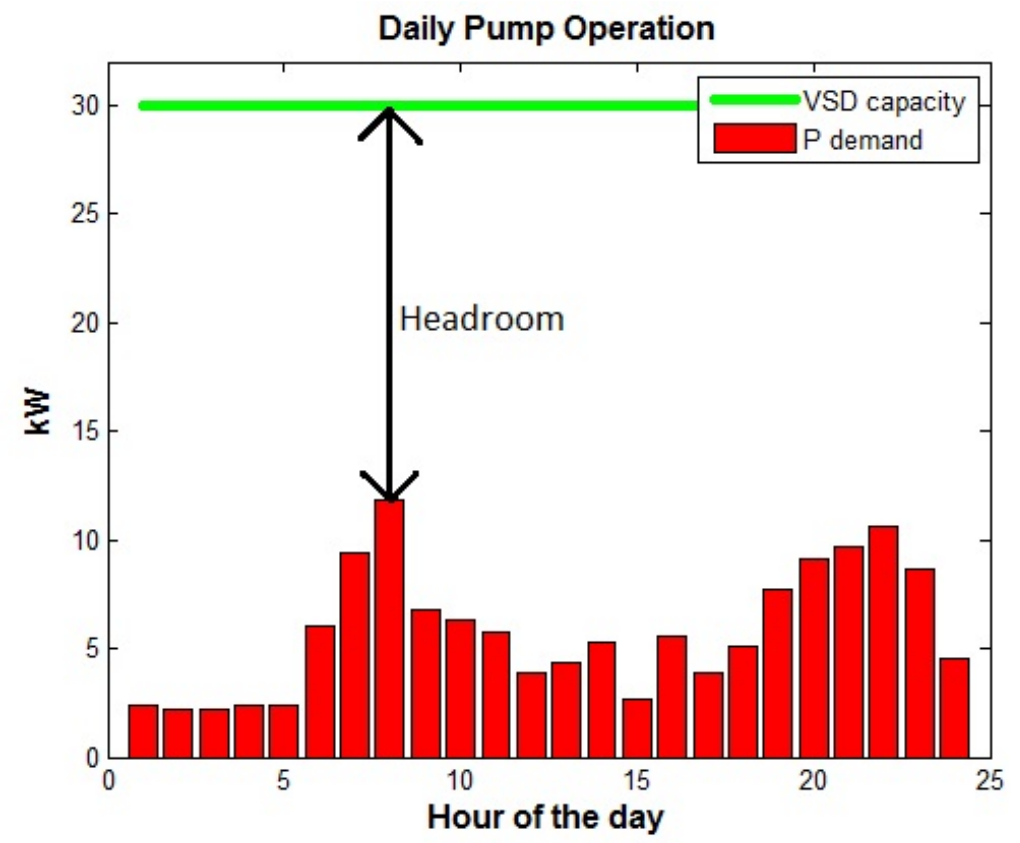

Figure 4.1: The headroom available in a sewage pump can be used to provide PF correction to a community with high PV DG penetration.

the minute-by-minute behavior of the wet well. When the water in the wet well (shown in blue) fills to the trigger height of 7 feet, the pump activates (shown in green) and draws power from the grid. The water level subsequently starts decreasing since the minimum discharge flowrate always exceeds the incoming flowrate (shown in red). Until the wet well entirely empties, the pump continues to draw power. Once the transducer at the bottom of the wet well is tripped, the pump deactivates and the cycle repeats. The figure displays this cyclic operation of the pump over the course of one day in December, where the blue peaks indicate transition points from filling to emptying the wet well, and the green outlining indicates the time during which the pump is on. The diurnal curve (i.e. incoming flowrates) is overlaid in red and provides a proxy for the rate at which the wet well fills and empties.

Due to the step-wise nature of the simulation, the water in the wet well often 


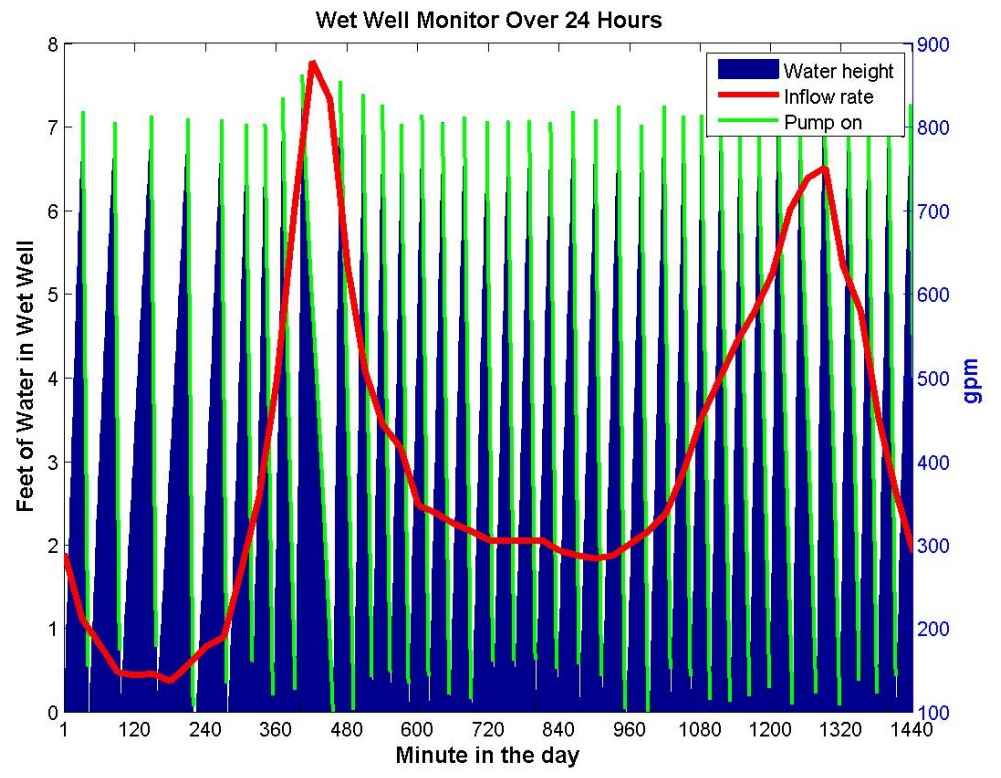

Figure 4.2: The wet well fills and empties as a function of net flowrate.

exceeds or falls below the trigger heights for pump activation or deactivation. The most "overflow" above the trigger height is 0.62 feet, which equates to approximately 668 gallons; the most "underflow" below the trigger height is -0.7 feet, which equates to approximately 754 gallons. In reality, these small deviations from the trigger heights would not significantly alter the pump's operation because the transducers are situated such that buffer volume exists at the top and bottom of the wet well. Additional transducers activate back-up pumps if this buffer volume becomes fully occupied.

\subsection{PF Improvement}

Figure 4.3 displays the shift in PF distribution over the course of one day due to the support provided by the VSD for varying PV penetrations. The red curve displays the PF distribution in the load pocket before reactive power from the VSD is applied; the blue curve displays the PF distribution after local support 

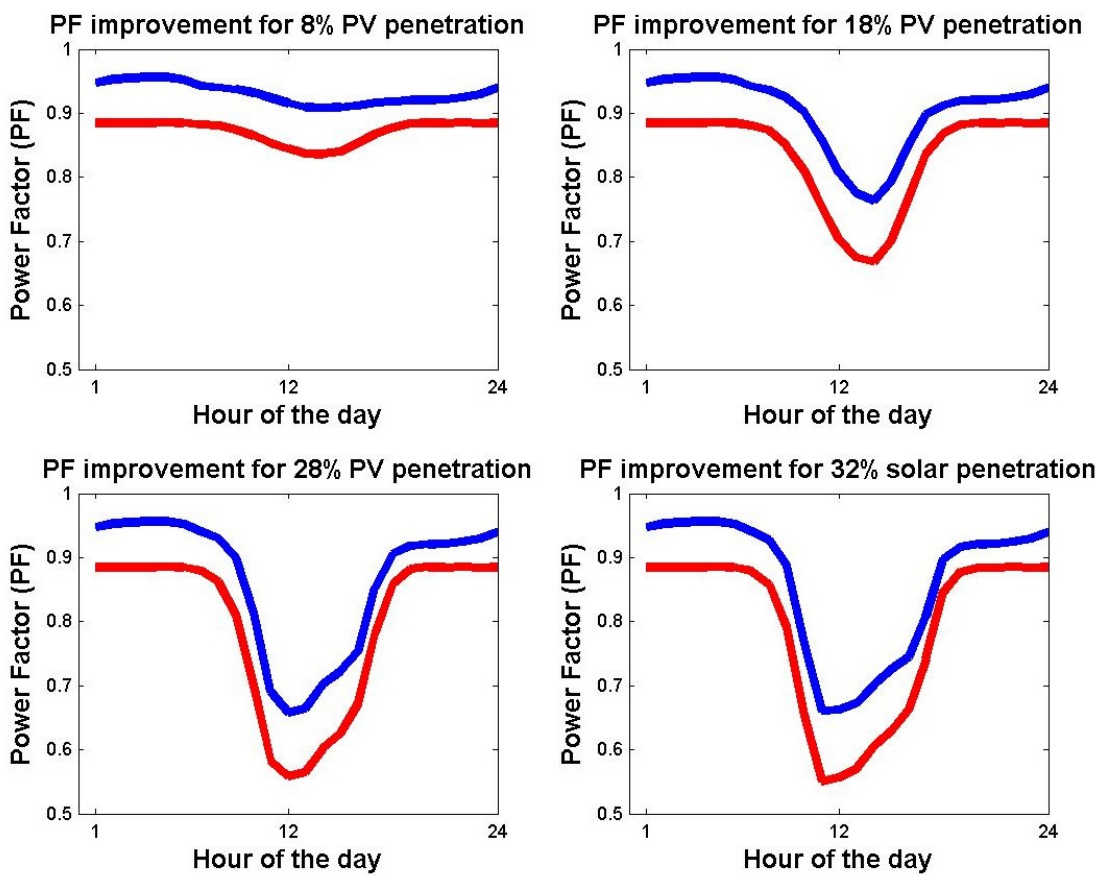

Figure 4.3: As PV penetration increases, PF degrades more substantially (from 0.87 ), especially during the hours of peak PV generation.

from the VSD eases reactive power demand from the distribution lateral. Given the minimal size $(30 \mathrm{~kW})$ of the motor load to which the VSD is applied, the (average) PF improvement displayed is significant, especially considering the additional correction possible if multiple, geographically consolidated motor loads could provide reactive power compensation to the same load pocket. Initial reactive power demand of the load pocket equates to a $\mathrm{PF}$ of 0.87 , which is the annual average of the randomized values between 0.86 and 0.91 .

Moving from lowest (8\%) to highest (32\%) PV penetration, where PV penetration is now presented as a ratio of the load pocket's maximum PV generation to its maximum consumption, Figure 4.3 displays the negative ramifications of PV DG on distribution PF. PF degradation is most significant around noontime, when PV power output is typically highest. The VSD provides maximum correction during 
these hours of lowest PF. Less correction is observed during the early morning when PV generation is nearly zero and PF degradation is not experienced. However, reactive power offered from the VSD is most likely to lift PF above 0.95 during these pre-dawn hours when the PF boost required (due to the load pocket's initial consumption PF) is lowest. Results confirm this assumption; for all PV penetrations, the VSD lifts PF above 0.95 during five hours of the day, all of which fall between 1 a.m. and 5 a.m, inclusive.

Table 4.1: PF correction is highest (on a percentage basis) for hours during which $\mathrm{PV}$ generation is also highest.

\begin{tabular}{|c|c|c|c|c|c|c|c|c|c|c|c|c|}
\hline & \multicolumn{12}{|c|}{ PV Penetration } \\
\hline & \multicolumn{2}{|c|}{$8 \%$} & \multicolumn{2}{|c|}{$12 \%$} & \multicolumn{2}{|c|}{$18 \%$} & \multicolumn{2}{|c|}{$23 \%$} & \multicolumn{2}{|c|}{$28 \%$} & \multicolumn{2}{|c|}{$32 \%$} \\
\hline & $\% \uparrow \mathrm{PF}$ & $\mathrm{hr}$ & $\% \uparrow \mathrm{PF}$ & $\mathrm{hr}$ & $\% \uparrow \mathrm{PF}$ & $\mathrm{hr}$ & $\% \uparrow \mathrm{PF}$ & $\mathrm{hr}$ & $\% \uparrow \mathrm{PF}$ & $\mathrm{hr}$ & $\% \uparrow \mathrm{PF}$ & $\mathrm{hr}$ \\
\hline Min & 4.1 & 20 & 4.1 & 20 & 4.1 & 20 & 4.1 & 20 & 4.1 & 20 & 4.1 & 20 \\
\hline Max & 19.8 & 11 & 18.3 & 11 & 17.0 & 12 & 14.9 & 12 & 11.8 & 14 & 8.7 & 14 \\
\hline
\end{tabular}

The seasonal variation in PF correction displayed on the left y-axis in Figure 4.4 is predominantly a function of the load pocket's reactive power demand, shown on the right y-axis. PF improvement is greatest during the non-summer months (i.e. winter and spring) when load pocket consumption is lowest and the load pocket's unmet gap of reactive power $\left(Q_{g a p}\right)$ is consequently least. When $Q_{g a p}$ is lower, the incremental correction provide by each unit of local supply $\left(Q_{l s}\right)$ is amplified. The figure illustrates this point by plotting all of these values, in addition to PV generation $\left(P V_{\text {gen }}\right)$, for the $32 \% \mathrm{PV}$ penetration case. Data in the figure represent results using an initial load PF of 0.87 and an electrical efficiency of $92 \%$.

Figure 4.4 shows that PF improvement is not only lowest during the summer, but also converges for various PV penetrations during that time. This convergence corresponds directly with the peak of $Q_{g a p}$, or the season during which power con- 


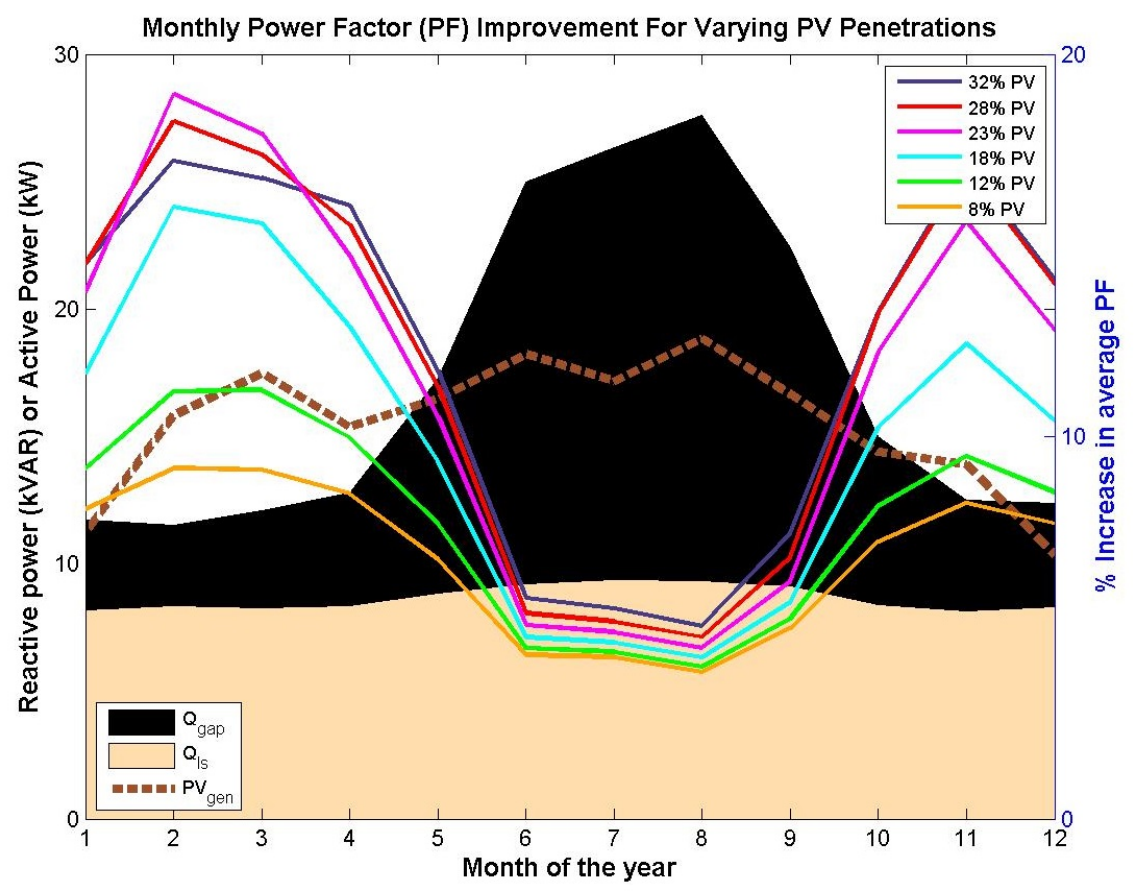

Figure 4.4: $\mathrm{PF}$ correction from the VSD is least effective during the summer when load and thus reactive power demand are highest (for a given PF).

sumption is highest. Although $P V_{\text {gen }}$ and $Q_{l s}$ fluctuate throughout the year, they do not do so nearly as dramatically as does $Q_{g a p}$. In particular, neither of these monthly distributions are characterized by a standard deviation greater than 2.6 ( $\mathrm{kW}$ or $\mathrm{kVAR}$ ); whereas, the standard deviation of $Q_{\text {gap }}$ is $6.3 \mathrm{kVAR}$. As a result, the VSD not only contributes more reactive power on a percentage basis during the non-summer months, but the incremental effect of increasing PV penetration is also more apparent. During the summer, these incremental effects are lost when considering the magnitude of the increase in power consumption, and thus local reactive power demand. 


\subsection{Economic Viability of the Proposed Solution}

The left y-axis in Figure 4.5 provides context for the utility payment necessary to achieve full payback (i.e. NPV=0) in the number of years specified. Note that the wavelike nature of the utility payment is driven by the unequal monthly cash flows of energy and demand savings.

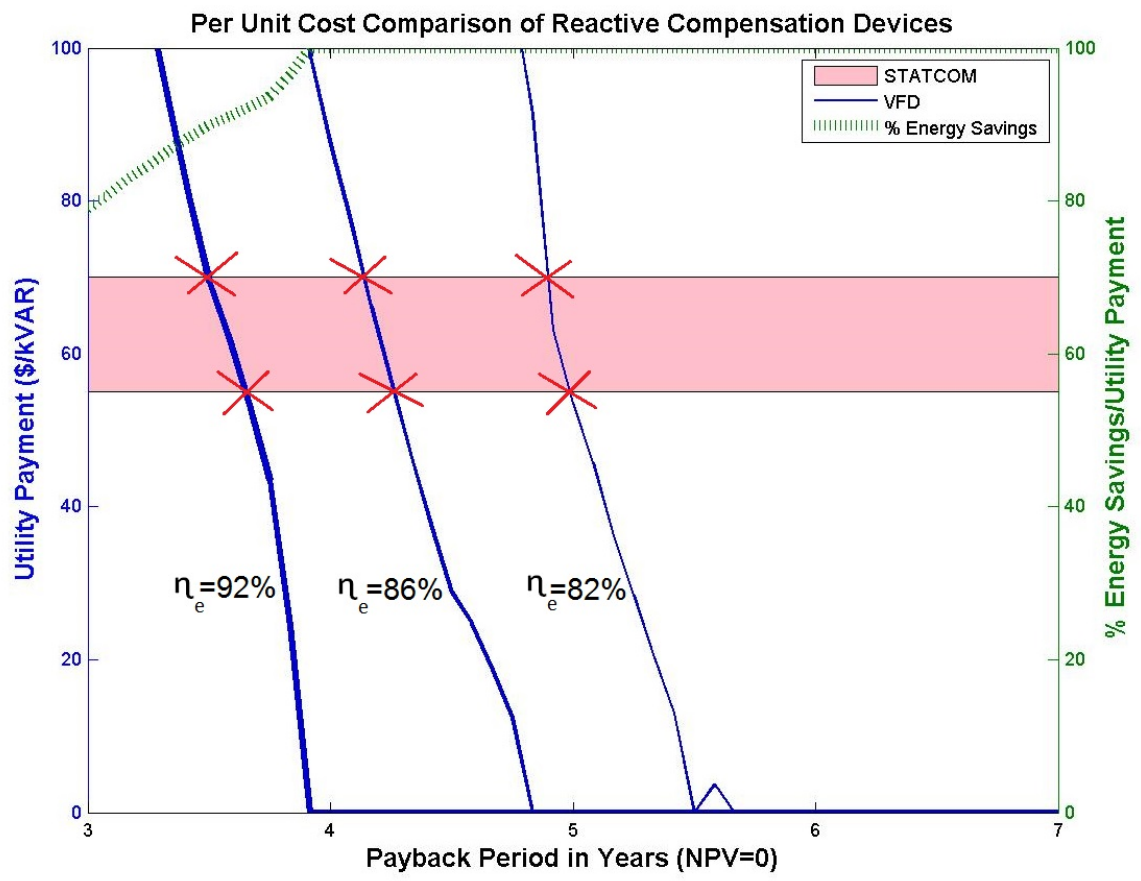

Figure 4.5: PF correction from the VSD is competitive with exiting utility solutions at a 3.5 customer payback.

The utility payment is derived as described in the methodology section and represents the upfront cost per unit of reactive power supplied to achieve the specified payback period. Although the utility payment would likely be spread across a number of installments, the NPV of those payments most aligns with total turnkey installed price, which is the value used to calculate the range of per unit costs associated with PF correction from a STATCOM as displayed by the pink block in Figure 4.3 [3]. The blue lines in the figure correspond to the evolution of the utility payment for various 
values of electrical efficiency as the desired payback period of AWU increases. As expected, the payment decreases as electrical efficiency increases and as the commercial customer commands a less aggressive payback schedule. The intersection point of the pink block with any of the three blue lines corresponds to the payback period required to achieve a competitive per unit cost of local PF correction from the VSD. The thickest blue line corresponds to an electrical efficiency of $92 \%$ and represents the most compelling argument, at a 3.5 year payback, for AWU to invest in an AFE VSD for the pump. Further discussion of the solution is based on the $92 \%$ electrical efficiency case.

The green curve shown on the right y-axis in Figure 4.5 represents the percent of discounted cash flow in any particular month that can be attributed to energy and demand savings versus the utility payment. At a 3.5-year payback period, $90 \%$ of the discounted cash flow is due to energy and demand savings. The utility payment is uncompetitive at shorter payback periods because the operational savings alone are inadequate to offset the upfront investment. It takes nearly four years for the utility payment to become competitive with the per unit cost of PF correction from a STATCOM, at which point energy and demand savings have accumulated and dominate the cumulative NPV. For a different application in which a VSD would achieve considerable energy and demand savings in the first few years of the drive's operation, the investment would not only be more attractive to the commercial customer, but also the utility payment required would be more competitive with legacy, dynamic solutions. 


\section{Chapter 5}

\section{Conclusion}

The results herein provide an introduction to the potential for an AFE VSD to regulate distribution grid voltage. The technical capability and economic feasibility described represent first-order findings from a specific test case of the proposed solution for dynamic PF correction. The appropriateness of using an AFE VSD as a grid device is highly dependent on the type and location of the motor load to which the drive is connected.

The forthcoming changes to IEEE 1547 that would enable the solution proposed by this research are a first step towards the use of third-party voltage regulation. Although liability and depreciation issues are not covered by this analysis, they are important considerations when evaluating the economic viability and reliability of a dynamic voltage regulation solution owned by an entity other than the utility. Further, choosing an appropriate controls architecture to prevent competition among voltage regulators within close proximity is of critical importance. Regardless of these potential limitations, the first-order conclusions presented herein justify further exploration of the use of VSDs as dynamic voltage regulators. Even if smart inverters adequately correct voltage fluctuations caused by PV DG, other drivers for dynamic, distribution-level PF correction exist, and the provision of reactive power from devices like VSDs represents an efficient use of latent resources. 


\section{Bibliography}

[1] Energy Efficiency and Renewable Energy, "Adjustable Speed Drive Part-Load Efficiency ," tech. rep., Department of Energy Advanced Manufacturing Office, 2012.

[2] Austin Energy, "Commercial Electric Rates \& Line Items."

[3] F. F. Li, J. Kueck, T. Rizy, and T. King, "A Preliminary Analysis of the Economics of Using Distributed Energy as a Source of Reactive Power Supply," tech. rep., Oak Ridge National Lab, 2006.

[4] Greentech Media, "The Grid Edge: Grid Modernization in the Age of Distributed Generation," tech. rep., 2013.

[5] F. M. Uriarte and R. E. Hebner, "Impact of Residential Photovoltaic Generation and Electric Vehicles on Distribution Transformers Progress Report \#1," tech. rep., Center for Electromechanics, 2013.

[6] John McDonald, "Solar Power Impacts Power Electronics in the Smart Grid," Power Electronics, 2013.

[7] San Diego Gas \& Electric, "Inverter Technical Standards Proposal," tech. rep.

[8] Peter Sauer, Applied Mathematics for Restructured Electric Power Systems. Springer, 2005.

[9] H. Li, F. Li, Y. Xu, D. T. Rizy, and S. Adhikari, "Autonomous and Adaptive Voltage Control Using Multiple Distributed Energy Resources," in IEEE Transactions on Power Systems, 2013. 
[10] Pacific Gas \& Electric Company, "Economics of Power Factor Correction in Large Facilities, >400kW," tech. rep., 2007.

[11] M. Lowe, R. Golini, and G. Gereffi, "U.S. Adoption of High-Efficiency Motors and Drives: Lessons Learned," tech. rep., Center on Globalization, Governance \& Competitiveness, Duke University, 2010.

[12] Kelly Sanders, "Evaluating the Energy Consumed for Water Use in the United States," Environmental Research Letters, 2012.

[13] Allison Lantero, Department of Energy, "The War of the Currents: AC vs. DC Power."

[14] R. O’Neill, M. Cain, D. Mead, D. Bandera, D. Withnell, Z. Salihi, and D. Sharma, "Principles for Efficient and Reliable Reactive Power Supply and Consumption," tech. rep., Federal Energy Regulatory Commission, 2005.

[15] Dave Kanye, Opower. Personal Communication.

[16] Peter Sauer, "What is Reactive Power," tech. rep., Power Systems Engineering Research Center, 2003.

[17] PowerWorld Corporation, "Steady State Power System Security Analysis with PowerWorld Simulator," tech. rep., 2012.

[18] Carrier Corporation, "Operation and Application of Variable Frequency Drive (VFD) Technology," tech. rep., 2005.

[19] John Merrell, "The Importance of the X/R Ratio in Low-Voltage Short Circuit Studies," tech. rep., Power Systems Engineering, 1999.

[20] National Grid, "An Introduction to Reactive Power," tech. rep., 2001. 
[21] Charles J. Murray, "Reliability Analysis of Single-Phase Photovoltaic Inverters With Reactive Power Support," Master's thesis, University of Illinois at UrbanaChampaign, 2010.

[22] Clayton Stice, Austin Energy. Personal Communication.

[23] H. W. Beaty and D. Fink, Standard Handbook for Electrical Engineers. McGraw Hill Professional, 2012.

[24] Nicholas Miller, General Electric. Personal Communication.

[25] John Mcdonald, Smart Grids: Infrastructure, Technology and Solutions. CRC Press, 2013.

[26] A. Ellis, R. Nelson, E. Engeln, R. Walling, J. McDowell, L. Casey, E. Seymour, W. Peter, C. Barker, and B. Kirby, "Reactive Power Interconnection Requirements for PV and Wind Plants - Recommendations to NERC," tech. rep., Sandia National Lab, 2012.

[27] GridCo Systems, "Intelligent Power Management and the Future of the Distribution Grid," tech. rep., 2013.

[28] M. T. Burr, M. J. Zimmer, B. Meloy, J. Bertrand, W. Levesque, G. Warner, and J. Mcdonald, "Minnesota Microgrids: Barriers, Opportunities, and Pathways Toward Energy Assurance," tech. rep., Microgrid Institute, 2013.

[29] T. Beach, A. Kozinda, and V. Rao, "Advanced Inverters for Distributed PV: Latent Opportunities for Localized Reactive Power Compensation," tech. rep., Clean Coalition, 2013.

[30] Siemens, "Active Front End Simovert Masterdrives," tech. rep. 
[31] Flygt, "VFD Recommendations," tech. rep., ITT Industries, 2002.

[32] Siemens Technical Education Program (STEP), "Basics of AC Motors."

[33] Hydraulic Institute and Europump and US Department of Energy, "Variable Speed Pumping - A Guide to Successful Applications," tech. rep., 2004.

[34] T. Neuberger and S. B. Weston, "Variable frequency drives: energy savings for pumping applications," tech. rep., Eaton Corporation, 2012.

[35] M. R. Lindeburg, Civil Engineering Reference Manual for the PE Exam. Professional Publications, Inc., 2012.

[36] City of Austin, "About Austin Water Utility."

[37] Pecan Street Research Institute, "What is Pecan Street."

[38] R. Salazar and C. Salls, "Energy Consumption and Cost Comparison of Constant Versus Variable Speed Pumps at the Barton Creek, Rattan Creek, Shoal Creek, and Taylor Slough Lift Stations," tech. rep., City of Austin Water and Wastewater Utility, 1997.

[39] Joe Smith, Austin Water Utility. Personal Communication.

[40] Joshua Rhodes, University of Texas at Austin. Personal Communication.

[41] power-one, "AURORA UNO Photovoltaic Inverters PVI-5000/6000-TL Technical Manual," tech. rep., ABB, 2013.

[42] Tom Rizy, "Volt/VAR Optimization, Dynamic Volt/Var Control." EUCI Conference Talk.

[43] Austin Energy, "Power Factor Adjustment." 
[44] Emory University, "Curve Fitting," tech. rep.

[45] Aqua Engineering, "Lift Station Maintenance Guide," tech. rep., 2009.

[46] Tony Rizk, Austin Water Utility. Personal Communication.

[47] C. Burt, X. Piao, and F. Gaudi, "Electric Motor Efficiency Under Variable Frequencies and Loads," tech. rep., Irrigation Training and Research Center, 2006.

[48] Perry Steger, Specific Energy. Personal Communication.

[49] A. Maknouninejad, N. Kutkut, I. Batarseh, and Z. Qu, "Analysis and control of PV inverters operating in VAR mode at night," in Innovative Smart Grid Technologies, 2011.

[50] Linda Rickard, Austin Energy. Personal Communication.

[51] Emerson Industrial Automation, "Active Front End Advanced Harmonic Reduction Technology," tech. rep., 2012.

[52] Control Techniques. Personal Communication.

[53] David Greene, Austin Water Utility. Personal Communication.

[54] Seifedine Kadry, Mathematical Formulas for Industrial and Mechanical Engineering. Elsevier Insights, 2014. 